\title{
To Believe or Not to Believe: Stereotypes About agnostics
}

by

Veronica Nilendra Zivana Bergstrom

A thesis submitted in conformity with the requirements for the degree of Master of Arts

Department of Psychology

University of Toronto

(C) Copyright by Veronica Nilendra Zivana Bergstrom 2018 


\title{
To Believe or Not to Believe: Stereotypes About agnostics
}

\author{
Veronica Nilendra Zivana Bergstrom \\ Master of Arts \\ Department of Psychology \\ University of Toronto
}

2018

\section{Abstract}

The present study investigated which stereotypes agnostics share with atheists, and which stereotypes are unique to each group. In Study 1, participants reported stereotypes that they believed society held about agnostics, atheists, Christians, and Muslims. Common stereotypes for agnostics were indecisive and questioning, but for atheists were immoral and intolerant. In Study 2, participants rated how representative 10 key traits from Study 1 were of agnostics, atheists, and four religious groups. Results revealed that agnostics were stereotyped less negatively than atheists. In Study 3, participants had to judge whether a target's actions, such as being immoral, morally indecisive, or indecisive in general were representative of an agnostic/atheist/Christian/Muslim. Inconsistent with Studies 1 and 2, no significant differences were found for perceptions of agnostics versus atheists. Findings from Studies 1-2 suggest that nonreligious individuals are sometimes viewed as a heterogeneous group, but future research must determine when stereotypes converge and diverge. 


\section{Acknowledgments}

I would like to thank my supervisor, Dr. Alison Chasteen, for her invaluable guidance and support. Secondly, I would like to thank my subsidiary advisor, Dr. Jason Plaks, for his feedback and expertise. Lastly, I would like to thank my external examination committee member, Dr. Wil Cunningham, for his time and insight. 


\section{Table of Contents}

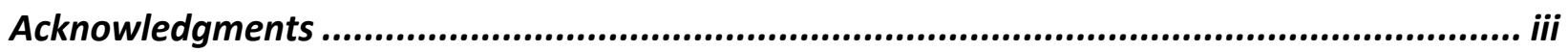

Table of Contents...................................................................................................................... iv

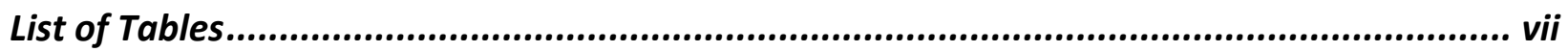

List of Figures............................................................................................................................. vii

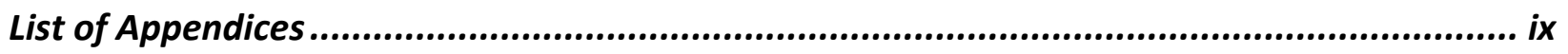

Chapter 1 Introduction ........................................................................................................ 1

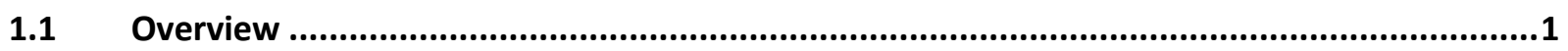

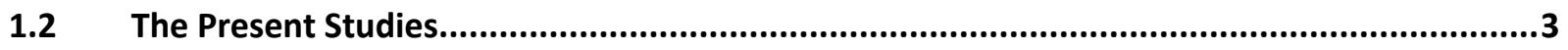

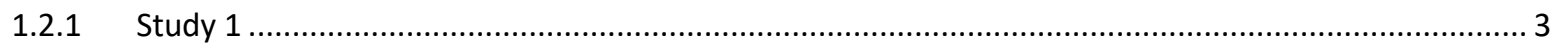

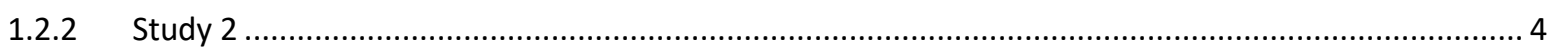

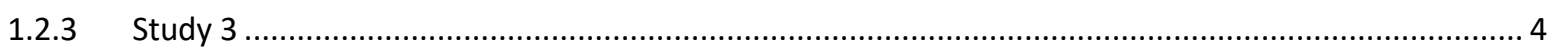

Chapter 2 Study 1 ............................................................................................ 5

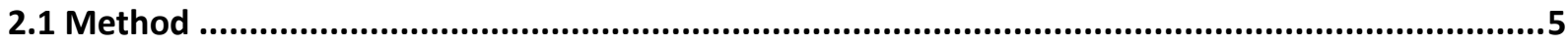

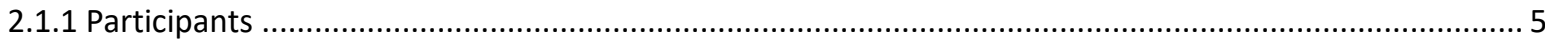

2.1.2 Procedure

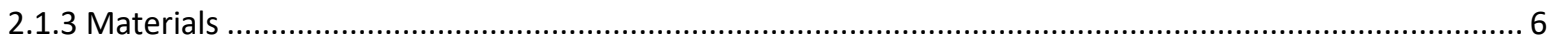

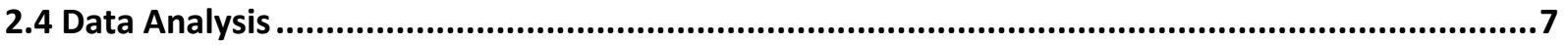

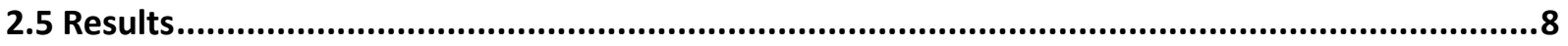

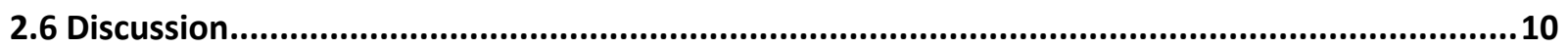

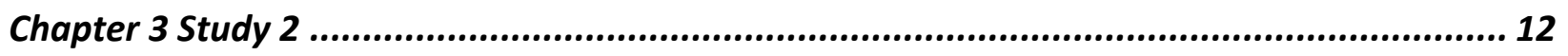

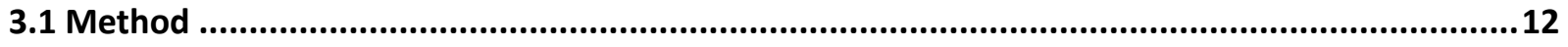

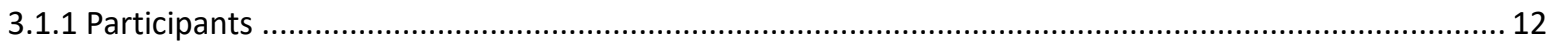

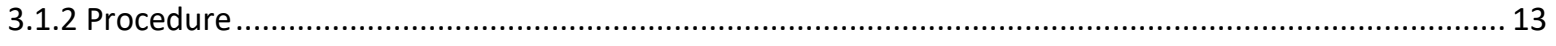

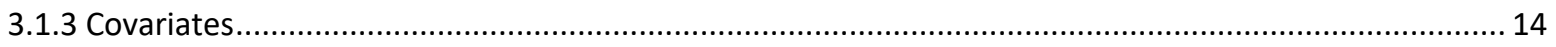

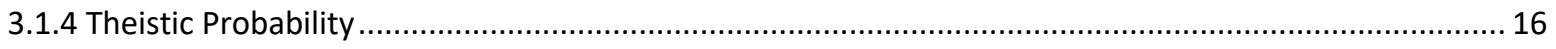

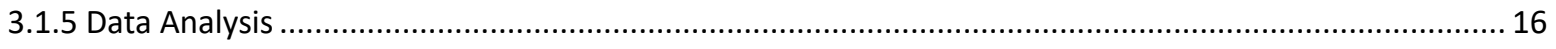




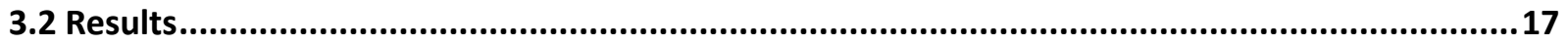

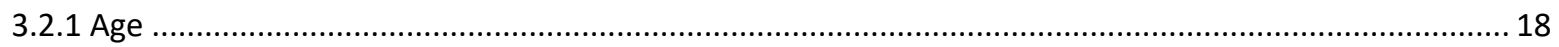

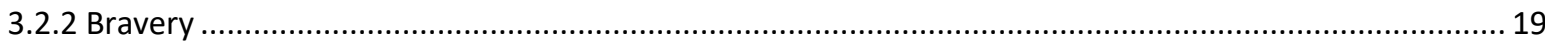

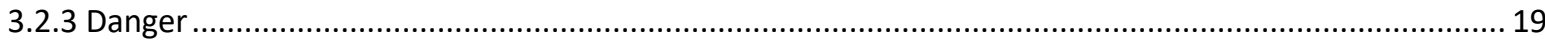

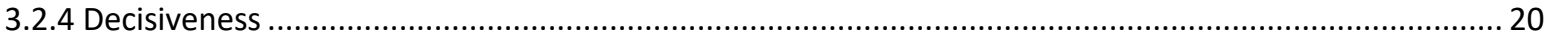

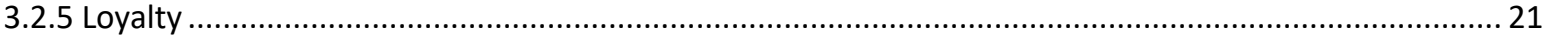

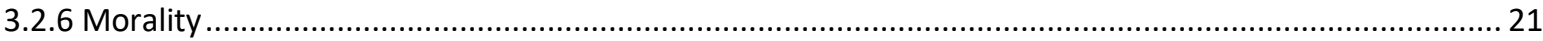

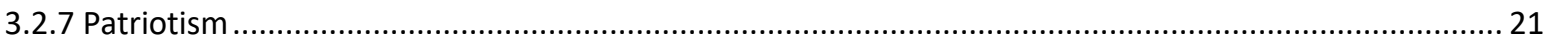

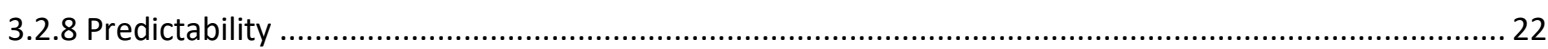

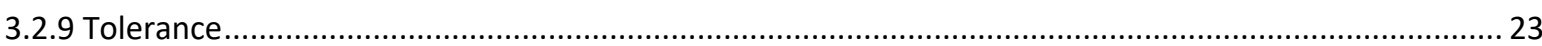

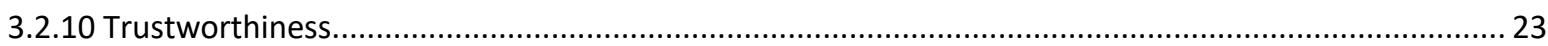

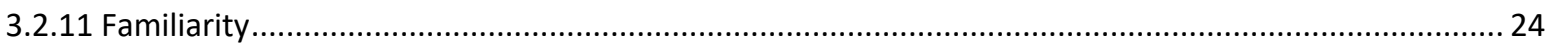

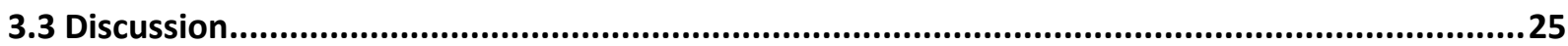

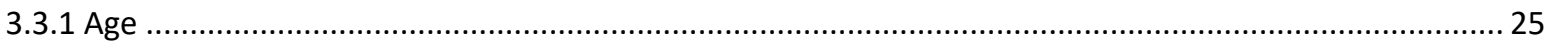

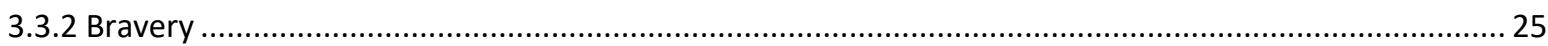

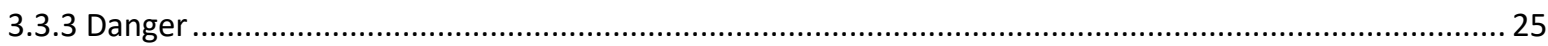

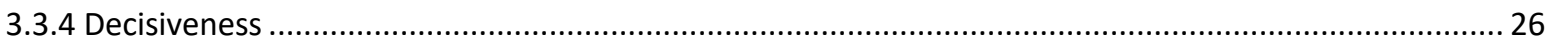

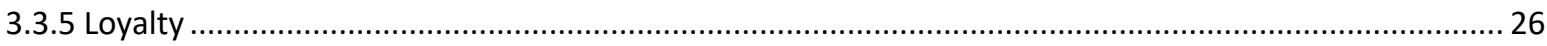

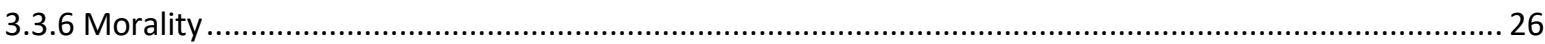

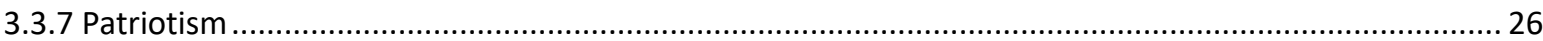

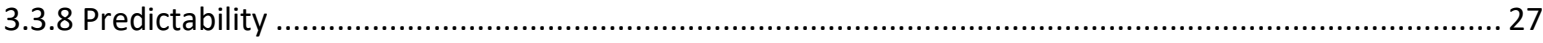

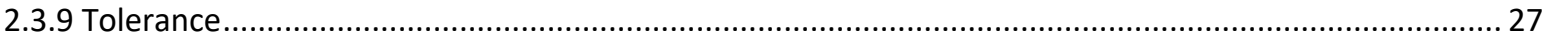

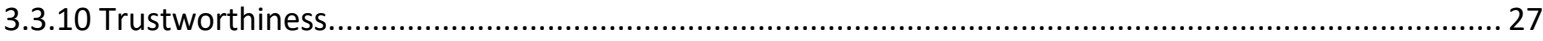

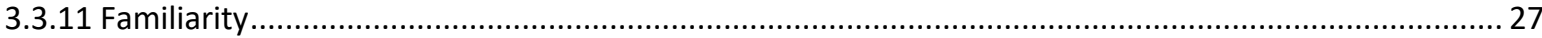

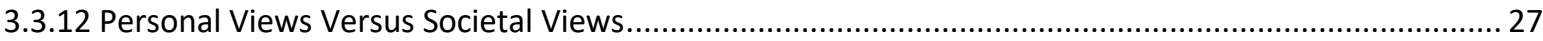

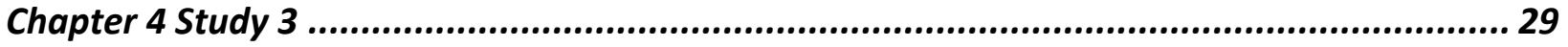

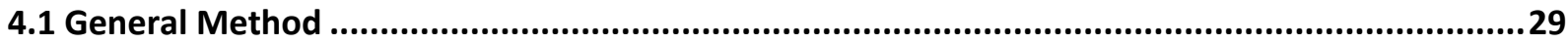

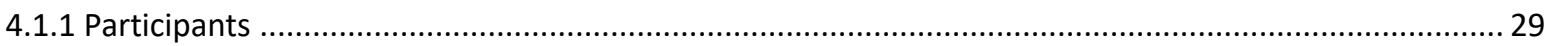

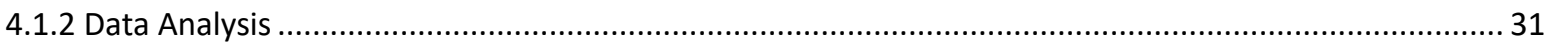

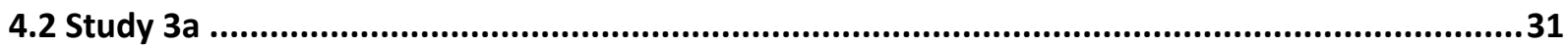

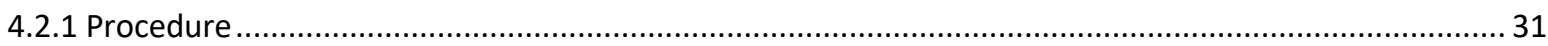

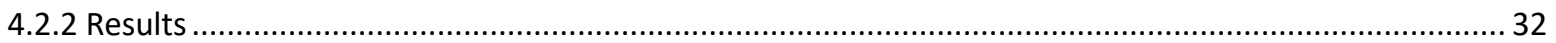

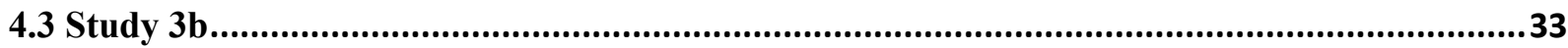

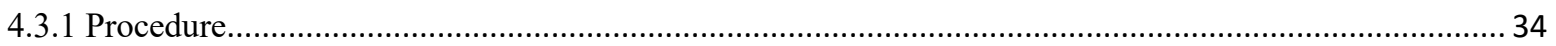


4.3.2 Results

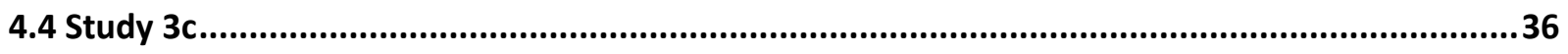

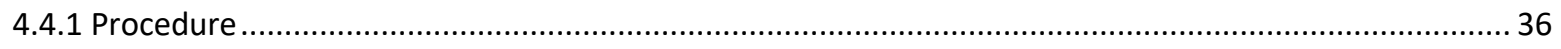

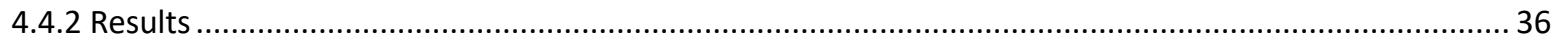

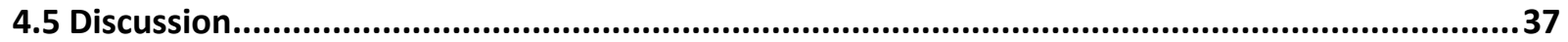

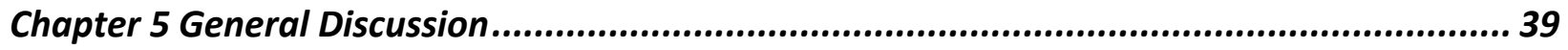

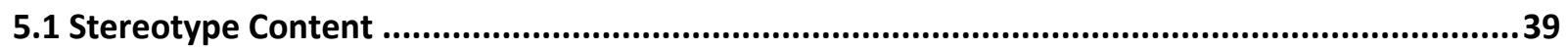

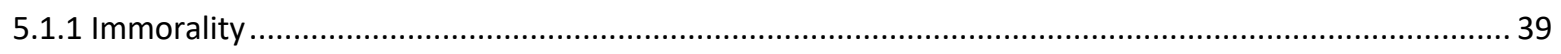

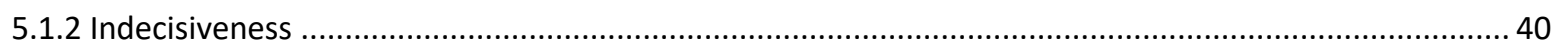

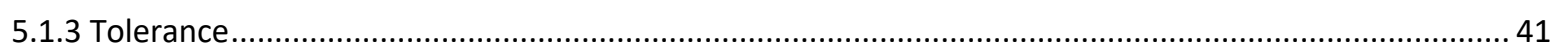

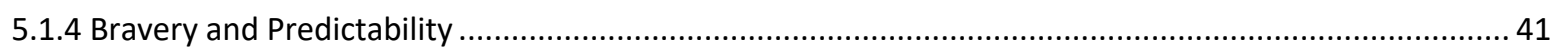

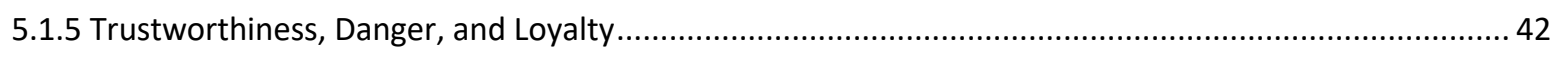

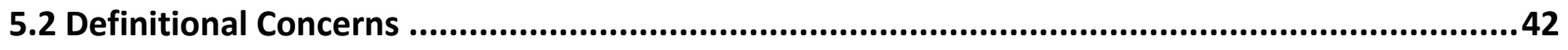

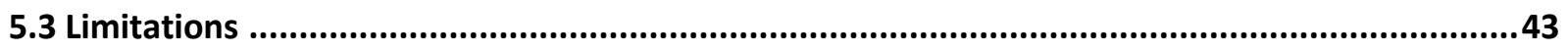

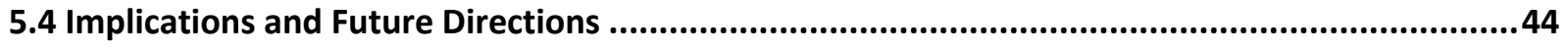

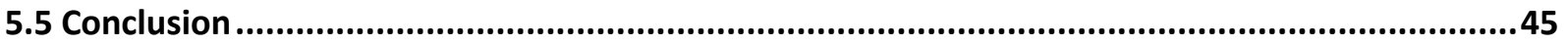

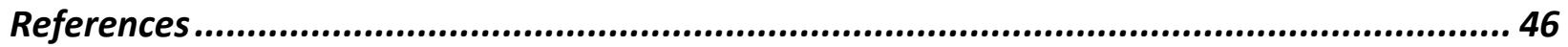

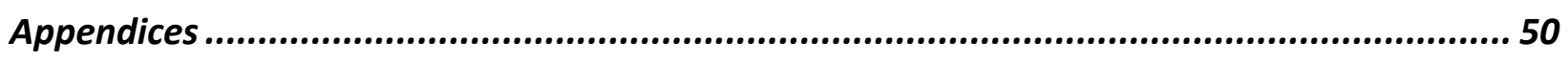




\section{List of Tables}

Table 1. Demographic Breakdown of Study 1

Table 2. Frequencies of Stereotypes for Agnostic, Atheists, Christians, and Muslims

Table 3. Demographic Breakdown of Study 2

Table 4. Contrasts for the MLM Models

Table 5. Descriptives for Age, Bravery, and Danger

Table 6. Descriptives for Decisiveness, Loyalty, and Morality

Table 7. Descriptives for Patriotism, Predictability, and Tolerance

Table 8. Descriptives for Trustworthiness and Familiarity

Table 9. Demographic Breakdown of Study 3

Table 10. Study 3a Odds Ratios Summaries

Table 11. Study 3b Odds Ratio Summaries

Table 12. Study 3c Odds Ratio Summaries 


\section{List of Figures}

Figure 1. Proportion of conjunction errors as a result of condition when participants read about an individual acting immoral.

Figure 2. Proportion of conjunction errors as a result of condition when participants read about an individual acting indecisive on morality.

Figure 3. Proportion of conjunction errors as a result of condition when participants read about an individual acting indecisive on an issue unrelated to morality. 


\section{List of Appendices}

Appendix A. Definitions

Appendix B. Study 1 - Generated Definitions for Agnostics and Atheists

Appendix C. Study 1 Dictionary

Appendix D. Study 1 - Chi-Square Results for Definitions Provided vs. Definitions Generated 


\section{Chapter 1}

\section{Introduction}

\subsection{Overview}

America's national motto is "in God we trust." However, nonreligious individuals now constitute almost one-quarter of America's population (Pew Research Center, 2012). In fact, they are the second largest "religious" group next to Christians, being more common than Jewish people, Muslims, Hindus, Sikhs, and Buddhists combined. Although the prevalence of non-religious individuals has risen, atheists are the least accepted minority group in the United States (Edgell, Gerteis, \& Hartman, 2006) and face discrimination such as ostracism, coercion into participating in religious activities, slander, hate crimes, and the denial of opportunities (Hammer, Cragun, Hwang, \& Smith, 2012). For example, Americans are the least likely to support an atheist candidate compared to any other group, including female, LGBTQ, Black, Hispanic, and Muslim individuals (Franks \& Scherr, 2014; Jones, 2012). And although it is not enforced, it is illegal for atheists to hold public office in Tennessee, Maryland, Texas, Arkansas, Mississippi, and North and South Carolina (Goodstein, 2014). When it comes to a presidential candidate, $70 \%$ of Republicans and $42 \%$ of Democrats report that knowing a candidate is atheist would negatively impact their support for that candidate (Pew Research Center, 2014). Because the nonreligious continue to face discrimination in a variety of domains, it is important to understand why this is so.

Researchers examining biases toward nonreligious individuals often group atheists and agnostics together when comparing theists to non-theists. This categorization may be problematic as atheists and agnostics have different worldviews: atheists believe that there is no God, whereas agnostics believe God's existence is unknown and/or unknowable. Thus, important differences may emerge when we investigate them individually. In order to reduce prejudice and discrimination against nonreligious individuals, it is imperative that we develop a better understanding of the stereotypes that drive discrimination toward different members of this group. Although some research has examined perceptions of atheists (Galen, William, \& Ver Way, 2014; Gervais, 2014; Wright \& Nichols, 2014), social psychologists have yet to examine stereotypes that are specific to agnostics.

Atheists are not a highly homogenous group and are relatively inconspicuous and innocuous. So why do they receive such high levels of prejudice and discrimination? Research has demonstrated that adults engage in more prosocial intentions and behaviours after being primed with concepts of God (Pichon, Boccato, \& Saroglou, 2007; Shariff \& Norenzayan, 2007). Furthermore, children behave more morally (e.g., refrain from cheating) when they believe others are watching, even if that being is supernatural (Piazza, Bering, \& Ingram, 2011). In fact, as cited in Gervais (2013), a 2002 Pew Research poll indicated that almost 50\% of Americans feel that believing in God is a requirement for morality and $60 \%$ believed that religious parents are necessary for instilling moral values in children. Thus, it is unsurprising that research about atheists suggests that perceptions of immorality drive distrust toward these individuals. In other words, there is a notion that individuals who believe in an omnipresent God act as 
though their actions are being monitored; because atheists do not believe in an omnipresent God, they are stereotyped as more likely to engage in immoral acts (Gervais, Shariff, \& Norenzayan, 2011).

Gervais (2014) further tested this assertion in a series of studies where he investigated how Americans intuitively judge the group membership of individuals committing a range of immoral deeds. Results indicated that people, including atheists themselves, judged others who committed acts of cannibalism, consensual incest, necrobestiality, and serial murder to be more representative of people who do not believe in God compared with Christians or Muslims. Furthermore, these acts were viewed as equally representative of rapists as they were atheists. Gervais chose to use a definition of atheism rather than the label 'atheist' in order to attenuate automatic negative reactions to the label. Additionally, he demonstrated how it is more likely belief in God, not religious community involvement, that is associated with perceptions of morality. Finally, not only do people judge immoral acts as more representative of atheists compared with theist groups (Gervais et al., 2011; Giddings \& Dunn, 2016), they also judge immoral acts more harshly if an atheist commits the act compared with a Christian (Wright \& Nichols, 2014).

Individuals who self-identify as atheist and agnostic experience greater discrimination compared to individuals who self-identify as a religious none (Cragun, Kosmin, Keysar, Hammer, \& Nielsen, 2012). Religious nones are individuals who do not identify with any religious or non-religious group; they may or may not believe in a higher power. The possibility that a person may identify as a religious none because they are dissatisfied with the current religious alternatives, not because they do not believe in a deity, makes them less of a threat compared with selfidentified atheists and agnostics who actively doubt or deny God's existence (Cragun et al., 2012). Because atheists and agnostics pose a greater threat to social order and theists' worldviews, it is unsurprising that they are larger targets for discrimination compared to religious nones. Comparing discrimination in different contexts, Cragun and colleagues found that self-identified atheists and agnostics are three times more likely to experience workplace discrimination, 3.4 times more likely to experience discrimination at school, and 2.5 times more likely to experience discrimination in social contexts compared to religious nones.

Not only are atheists perceived more negatively than religious nones, in certain contexts they are disliked and discriminated against more than other value-threatening stigmatized groups, such as homosexuals and Muslims (Cook, Cottrell, \& Webster, 2015; Jones, 2012). Because atheists are not bound by God to adhere to society's values, they are perceived to lack a moral compass, which in turn elicits feelings of moral disgust in individuals and drives behaviours to uphold current values and mitigate contamination by the outgroup (Cook et al., 2012; Cottrell $\&$ Neuberg, 2005). One way to mitigate contamination is to identify and censure individuals who violate moral values (for more on this idea see Robinson, Xu, \& Plaks, in press). Consistent with this idea, Cook et al. (2012) found that perceiving a threat to one's values increased discriminatory intent toward atheists, but not Muslims, homosexuals, or individuals with HIV. More specifically, undergraduates who read an article about moral decline in college students, compared to a control article, were less likely to support an atheist political candidate or support a local atheist business owner, and were less likely to believe that atheists should be included in the U.S. Supreme Court. 
Perceiving group discrimination and experiencing personal discrimination is associated with lower psychological and physical well-being in atheists who are both self-identified and theologically-consistent in their beliefs (Doane \& Elliot, 2015). However, in line with the rejection-identification model (Branscombe, Schmitt, \& Harvey, 1999), Doane and Elliot (2015) also found that those who perceived increased levels of discrimination were more likely to strongly identify as an atheist. Thus, there is likely a cyclical process between self-identification leading to greater discrimination and greater discrimination leading to stronger identification with the marginalized outgroup (Cragun et al., 2012; Doane \& Elliot, 2015; Jetten, Branscombe, Schmitt, \& Spears, 2001).

In summary, researchers have begun to investigate stereotypes about atheists and the levels of discrimination that they encounter - but what about agnostics? Statistically, self-identified agnostics comprise a larger proportion of the population than self-identified atheists (Pew Research Center, 2015). Yet, we do not know much about the unique stereotypes and discrimination they face. Some may argue that agnosticism should not be studied in contexts in which researchers are interested in the differences between believers and nonbelievers in God because agnosticism is related to knowledge, not belief (for example, Gervais, n.d.). More specifically, atheism versus theism is related to one's belief in God but agnosticism versus gnosticism is related to whether one believes God's existence can be known. Because they lie on different dimensions, a person could be an atheist or theist while also being agnostic. However, disregarding those who self-identify as purely agnostic when studying prejudice and stereotyping processes between different religious and nonreligious groups would exclude knowledge about the types of discrimination and biases that a significant proportion of the population may face. Thus, I argue that the considerable number of individuals who self-identify as agnostic warrants the need for research to be conducted on these individuals, regardless of agnostics' lack of mutual exclusivity with other groups.

\subsection{The Present Studies}

Due to the dearth of social psychological research on agnostics, the present study aims to investigate which stereotypes agnostics share with atheists, and which stereotypes are unique to each group.

\subsubsection{Study 1}

For the first study in my thesis, I aimed to identify the content of the agnostic stereotype and to determine the degree to which that content is unique versus similar to that of the atheist stereotype. Thus, in Study 1, I asked American participants to report up to five words or short phrases that relate to stereotypes they believe society holds about agnostics, atheists, Christians, and Muslims. I chose Christians as a comparison group because they are the majority group in the United States and I chose Muslims as a comparison group because they are the second most disadvantaged religious/nonreligious group next to atheists (Jones, 2012).

Although I expected there to be some stereotype content overlap with atheists, I predicted that agnostics would have other features that are unique to their group. Consistent with previous work, I believed that common stereotypes associated with atheists would be: immoral, untrustworthy, individualistic, opinionated, and rebellious (Gervais, 
2014; Harper, 2007). I hypothesized that agnostics, too, would be viewed as immoral, but not to the same degree as atheists. I predicted agnostics would also be seen as fence sitters and indecisive for not "picking a side."

Additionally, many, such as Dawkins (2006), may argue that it is not possible to neither believe nor disbelieve at the same time; therefore, I expected that agnostics would be viewed as cowardly or dishonest for not voicing their true beliefs. Additionally, I predicted that agnostics would be more likely to be viewed as unpredictable because in different contexts they may shift their beliefs to be more in line with atheists or with theists. As a result, this should also lead to them being viewed as untrustworthy. Finally, I hypothesized that agnostics would also be viewed as more open-minded or tolerant because they have not ruled out the viewpoints of atheists nor theists.

In line with previous work, I believed the common stereotypes associated with Christians would be: religious, good, honest, caring, friendly, loving, judgmental, and ignorant (Zafar \& Ross, 2015). Also in line with previous work, I believed the common stereotypes associated with Muslims would be: religious, pray, untrustworthy, violent, terrorist, strict, bad, and good (Sides \& Gross, 2013; Zafar \& Ross, 2015).

Using the stereotype content generated about these groups, I created dictionaries that contained the common stereotypes for each group (agnostics, atheists, Muslims, and Christians). These dictionaries will be used as a reference for future studies that investigate stereotypes and discrimination of different religious and nonreligious groups.

\subsubsection{Study 2}

In Study 2, I aimed to conceptually replicate the results of Study 1. However, individuals were asked to rate the representativeness of traits to the different groups rather than generate traits.

\subsubsection{Study 3}

For my final study, I aimed to further test the degree to which stereotypes of agnostics are similar (e.g., viewed as immoral) versus unique (e.g., viewed as indecisive) from those of atheists. Study 3 consisted of three separate experiments: one that tested immorality, one that tested indecisiveness regarding immorality, and one that tested indecisiveness in general. More specifically, individuals judged the group membership of a person who was engaging in one of the above-mentioned activities. When testing associations with atheists, agnostics, Christians, and Muslims, I hypothesized that individuals would associate immorality with atheists, followed by agnostics, but not with Muslims or Christians. In contrast, I predicted that individuals would associate indecisiveness regarding morality with agnostics, followed by atheists, but not with Muslims or Christians. Finally, I hypothesized that individuals would associate indecisiveness in general with only agnostics, not atheists, Muslims, nor Christians. The results of these studies are a first step in determining whether individuals use different criteria to judge someone's group membership as atheist versus agnostic. 


\section{Chapter 2}

\section{Study 1}

Study 1 assessed the stereotypes that individuals believe society holds about atheists, agnostics, Christians, and Muslims. With the resultant stereotype content, I created stereotype dictionaries for each group.

\subsection{Method}

\subsubsection{Participants}

One hundred twenty-seven Amazon Mechanical Turk (MTurk) participants were compensated \$1.25 USD for participating in this study. The only inclusion criterion was that they had to reside in the United States. I excluded participants with duplicate IP addresses and worker IDs from analysis. Furthermore, I checked longitude and latitude coordinates, and IP addresses to ensure that participants who completed the study outside of the United States were excluded as well. Additionally, I excluded participants who did not list stereotypes. The final sample size was 118 (see Table 1 for a demographic summary of participants). I based this sample size on previous qualitative work done in my lab.

Table 1

Demographic Breakdown of Study 1

Gender

Male

Theistic Probability 
Score of $>5$ on Dawkin's Scale (theist)

Religious Affiliation

Christian

Atheist

Agnostic

None

6

Other

2

\subsubsection{Procedure}

Participants were randomly assigned to one of two conditions. In Condition A, participants were provided with a definition of an agnostic, atheist, Christian, or Muslim (see Appendix A for definitions). After reading the definition, they listed up to five words or short phrases that relate to stereotypes most people hold about that group. Participants repeated these two steps until they had read definitions and listed stereotypes for all four groups. I randomized the order of the groups that were presented to participants. In Condition B, participants followed a near-identical procedure; however, rather than being provided with definitions, they generated their own definitions for each group before listing stereotypes. By including a definition-provided condition and definition-generated condition, I was able to investigate whether individuals often conflate atheism with agnosticism, and whether providing a definition influences stereotype content. After generating stereotypes, all participants responded to demographic and religiosity questions.

\subsubsection{Materials}

\subsubsection{Theistic Probability}

Participants completed the 1-item spectrum of theistic probability scale to assess their belief in a deity (Dawkins, 2006). Participants rated on a 7-point scale, ranging from 1(Strong Atheist: "I am 100\% sure that there is no God"”) to 7(Strong Theist: "I do not question the existence of a God, I KNOW he exists"), their certainty in God's existence. Higher scores indicate a stronger belief in God. 


\subsubsection{Religiosity}

If participants identified with a religious or non-religious group, they listed which one that was. Furthermore, they were asked to respond on a 7-point scale, ranging from 1(Not at all important) to 7(Extremely important) how important their religious/spiritual traditions are to them. Additionally, they rated on a 7-point scale, ranging from 1(Not at all involved) to 7(Extremely involved) how involved they are in their religious/spiritual group.

\subsubsection{Demographics}

Participants reported their age, gender, highest level of education, and political orientation. Participants responded on a 7-point scale, ranging from 1(Extremely liberal) to 7(Extremely conservative), to indicate their general political orientation.

\subsection{Data Analysis}

Two undergraduate research assistants (RAs) independently coded the data and then compared results. To begin, they removed all capitals, fixed typos, and changed plural words into singular words (e.g., terrorists into terrorist). They then conducted frequency counts of the stereotypes that participants used. After creating individual frequency counts, RAs merged their coding into one Excel spreadsheet. They highlighted disagreements and went over the list of disagreements individually. RAs then decided on whether to keep their responses the same or change them.

Next, RAs standardized the data by turning phrases into single-word expressions, when possible (e.g., 'not moral' into 'immoral'). RAs created roots by pruning words in the list. They included all possible synonyms to the root. This process ensured that conjugations and other variations of a word were included in the dictionary. Again, RAs highlighted disagreements and changed responses until they reached consensus.

After finalizing the stereotypes generated by participants, two additional RAs joined the team. RAs used the generated stereotypes as a starting point to find synonyms in thesauruses and online sources. Additionally, they searched for other stereotypes in academic and non-academic online sources (e.g., blog posts). After creating individual stereotype lists, RAs merged their coding into one Excel spreadsheet. Again, RAs highlighted disagreements and changed responses until they reached consensus. If RAs could not reach an agreement, then, I, the primary investigator would make the final decision; however, the RAs always managed to reach an agreement among themselves, so I never had to be a tie-breaker. Once the excel sheets were finalized, each stereotype was coded as being positive, neutral, or negative in valence. Synonyms were collected in order to have a pool of various stereotypes to draw from for future studies.

With the wordlists that contained only the words that participants generated themselves, synonyms were combined under a single term (e.g., "heartless" became "cold*”). I used http://www.thesaurus.com/ to decide how to group words together. To make changes, the excel sheets were loaded into Google's Open Refine Program. This allowed for words (e.g., "heartless") to be changed across all excel sheets simultaneously (e.g., to "cold*") to maintain 
consistency. Next, I dropped words that had a count of one for a single religious group and that was not listed for any of the other groups. Finally, I combined the between-subjects variable of definitions given versus definitions generated.

In order to assess how often participants conflated agnosticism with atheism, two RAs went through the list of generated definitions for atheists and agnostics and coded them as either being correct, conflated with the other group, or incorrect and unrelated definitionally to the other group. They used definitions from Wikipedia to aid in their judgments. When the RAs had disagreements, I, the primary investigator, made the final decision. For agnosticism, RAs had 77\% agreement; for atheism, RAs had 86\% agreement. The lower interrater reliability for agnosticism is discussed in the general discussion section.

I conducted statistical testing in R (Version 3.5.0). To test for differences between 26 stereotypes of atheists and agnostics, chi-square tests were performed with a Bonferroni adjustment of $\alpha=.05 / 26=.0019$. When chi-squares were significant, follow-up pairwise testing across all four groups was conducted with a Holm adjustment. Similarly, to test for differences between whether having a definition provided to participants influenced stereotype generation for agnostics and atheists, chi-square tests were performed with Bonferroni adjustments of $\alpha=.05 / 9=$ .0056 and $\alpha=.05 / 7=.0071$, respectively.

\subsection{Results}

For those who generated definitions, 55\% correctly defined agnosticism, $13 \%$ of participants reported a definition of atheism for agnosticism, and 32\% gave an incorrect definition of agnosticism that was unrelated to atheism. In contrast, 95\% of participants had a correct definition for atheism (see Appendix B for generated agnostic and atheist definitions).

The most common stereotypes for agnostics included indecisive, faithless, questioning, nonreligious, confused, immoral*, atheis*, kind*, scien*, and stupid. The asterisks signal that the preceding letters are a root to two or more similar words (e.g., kind* includes stereotypes of kind and kind-hearted). The most common stereotypes for atheists were immoral*, intoleran*, evil, satan*, arrogan*, mean*, nonreligious, faithless, rude, and bad. The most common stereotypes for Christians were kind*, religio*, intoleran*, charitable, judg*, hypocrit*, pushy, conservativ*, moral*, and faithful. Finally, the most common stereotypes for Muslims were terror*, intoleran*, danger*, violen*, religio*, religious headwear, backwards, evil, filth*, hard-headed, and Brown (see Appendix C for full dictionary results).

To test for differences between stereotypes of atheists and agnostics, I performed chi-squares tests (see Table 2 for complete results). Atheists were viewed as more evil, immoral, rude, and satanic than agnostics. In contrast, agnostics were viewed as more confused, indecisive, and kind than atheists.

Table 2

Frequencies of Stereotypes for Agnostic, Atheists, Christians, and Muslims 


\begin{tabular}{|c|c|c|c|c|c|}
\hline Word & Agnostic & Atheist & Christian & Muslim & Chi-Square \\
\hline angry & $1 \mathrm{a}$ & $8 a$ & $0_{a}$ & $5 \mathrm{a}$ & 12.072 \\
\hline arrogan* & $11_{\mathrm{a}}$ & $20_{a}$ & $8 \mathrm{a}$ & $0_{\mathrm{b}}$ & $22.891 * * *$ \\
\hline bad & $5 \mathrm{a}, \mathrm{b}$ & $14 \mathrm{a}$ & $1 \mathrm{~b}$ & $5 \mathrm{a}, \mathrm{b}$ & $15.332 * *$ \\
\hline cold* & $3_{\mathrm{a}, \mathrm{b}}$ & $10_{a}$ & $0_{\mathrm{b}}$ & $1_{\mathrm{a}, \mathrm{b}}$ & $17.961 * * *$ \\
\hline confus* & $17_{\mathrm{a}}$ & $4 b$ & $0_{\mathrm{b}}$ & $0_{b}$ & $38.823^{* * *}$ \\
\hline coward* & $8 \mathrm{a}$ & $0 \mathrm{a}$ & $0 \mathrm{a}$ & $1 \mathrm{a}$ & $20.275^{* * *}$ \\
\hline curious & $7 \mathrm{a}$ & $0_{\mathrm{a}}$ & $0_{\mathrm{a}}$ & $0 \mathrm{a}$ & $21.316^{* * *}$ \\
\hline evil & $6 a$ & $25 \mathrm{~b}$ & $0_{a}$ & $13_{\mathrm{a}, \mathrm{b}}$ & $34.688 * * *$ \\
\hline fence-sitters & $6 a$ & $0 \mathrm{a}$ & $0 \mathrm{a}$ & $0 \mathrm{a}$ & $18.232 * * *$ \\
\hline hard-headed & 2 & 5 & 3 & 11 & 9.718 \\
\hline immoral* & $16_{a}$ & $36_{b}$ & $0_{\mathrm{c}}$ & $1_{\mathrm{c}}$ & $71.329 * * *$ \\
\hline indecisive & $44 a$ & $1 \mathrm{~b}$ & $0 \mathrm{~b}$ & $0 \mathrm{~b}$ & $140.580 * * *$ \\
\hline indifferent & 6 & 1 & 0 & 0 & 14.356 \\
\hline intoleran* & $11_{a}$ & $33 b$ & $29 \mathrm{~b}$ & $70_{c}$ & $73.789^{* * *}$ \\
\hline kind* & $15_{a}$ & $1_{b}$ & $50_{c}$ & $2 b$ & $77.762 * * *$ \\
\hline mean* & $7 \mathrm{a}, \mathrm{b}$ & $20_{a}$ & $3 b$ & $9_{\mathrm{a}, \mathrm{b}}$ & $17.749 * * *$ \\
\hline neutral & $7 \mathrm{a}$ & $0_{a}$ & $0_{a}$ & $0_{a}$ & $21.316^{* * *}$ \\
\hline pushy & $0_{a}$ & $7_{\mathrm{a}, \mathrm{b}}$ & $20 \mathrm{~b}$ & $4 a$ & $31.039 * * *$ \\
\hline questioning & $22 a$ & $12 \mathrm{a}$ & $0_{b}$ & $0 \mathrm{~b}$ & $42.978 * * *$ \\
\hline rational & $11_{\mathrm{a}}$ & $7_{\mathrm{a}, \mathrm{b}}$ & $0_{b}$ & $0_{b}$ & $20.565^{* * *}$ \\
\hline rude & $3 \mathrm{a}$ & $15 \mathrm{~b}$ & $3 \mathrm{a}$ & $5_{\mathrm{a}, \mathrm{b}}$ & $16.119^{* *}$ \\
\hline
\end{tabular}




\begin{tabular}{|c|c|c|c|c|c|}
\hline satan* & $7 \mathrm{a}$ & $23 \mathrm{~b}$ & $0_{\mathrm{c}}$ & $0_{\mathrm{c}}$ & $50.261 * * *$ \\
\hline scien* & $14 a$ & $4_{a, b}$ & $0_{b}$ & $0_{b}$ & $30.265^{* * *}$ \\
\hline toleran* & $11_{\mathrm{a}}$ & $2 \mathrm{a}, \mathrm{b}$ & $1 \mathrm{~b}$ & $1 \mathrm{~b}$ & $19.486^{* * *}$ \\
\hline untrustworthy & 9 & 8 & 8 & 7 & 0.268 \\
\hline young & $9 \mathrm{a}$ & $4_{\mathrm{a}, \mathrm{b}}$ & $0_{b}$ & $0_{\mathrm{b}}$ & $17.323 * * *$ \\
\hline
\end{tabular}

$* * \mathrm{p}<.0019 ; * * * \mathrm{p}<.001$

Note. ${ }^{a}$ Groups that share subscripts indicate a nonsignificant difference. When the Chi-Square was significant, but all groups share a subscript, this means that significance did not remain after pairwise testing with a Holm adjustment. ${ }^{b}$ Asterisks signal that the preceding letters are a root to two or more similar words

To test for differences in stereotype content for the definition-provided vs. definition-generated agnostic and atheist conditions, I performed chi-square tests. Tests were computed for words where there was a count difference of five or more between the definition-provided versus - generated conditions. This resulted in nine tests between the agnostic conditions and seven tests between the atheist conditions. No differences were statistically significant using Bonferroni-adjusted alpha levels (see Appendix D for Chi-square results).

\subsection{Discussion}

Study 1 demonstrated that in general, individuals understood what an atheist is, but struggled when defining agnosticism. In addition to avoiding possible knee-jerk negative reactions to the labels of atheism and agnosticism, another reason for using definitions was to ensure that individuals would not conflate agnosticism with atheism. Because conflation occurred in $13 \%$ of cases and only $55 \%$ of cases defined agnosticism correctly, this study provides initial evidence that researchers should consider providing a definition for agnosticism when testing research questions about this group. It should be noted, however that the stereotype content that participants generated did not differ between groups who received a definition of agnosticism and those who did not.

Different stereotypes emerged across all four groups. The most common stereotypes for agnostics included indecisive, faithless, questioning, nonreligious, confused, immoral, atheist, kind, science, and stupid. To my knowledge, this is the first time stereotypes of agnostics have been investigated empirically. The most common stereotypes for atheists were immoral, intolerant, evil, satanic, arrogant, mean, nonreligious, faithless, rude, and bad. These findings are consistent with Harper (2007), who found that religious students stereotyped atheists as not religious, faithless, rebellious, anti-Christian, opinionated, argumentative, critical, and immoral. The most common stereotypes for Christians were kind, religious, intolerant, charitable, judgmental, hypocrite, pushy, conservative, moral, and faithful. These findings were consistent with Zafar and Ross (2015), who found Christians were 
stereotyped as religious, good, honest, caring, friendly, loving, judgmental, and ignorant. Finally, the most common stereotypes for Muslims were terror, intolerant, danger, violent, religious, religious headwear, backwards, evil, filthy, hard-headed, and Brown. These findings are also in line previous work that has found Muslims to be stereotyped as religious, untrustworthy, violent, terrorist, strict, and bad (Sides \& Gross, 2013; Zafar \& Ross, 2015).

Regarding stereotype content between atheists and agnostics, this study suggests that these two groups share many stereotypes but that they also differ in important ways. For example, although agnostics were viewed as immoral, they were considered less immoral than atheists. Furthermore, agnostics were viewed as kinder than atheists. However, individuals also viewed agnostics as more indecisive and confused than atheists. These differing stereotypes may result in different levels and types of prejudices that they experience compared with atheists. 


\section{Chapter 3}

\section{Study 2}

Study 2 aimed to conceptually replicate the results of Study 1. I tested whether various traits were representative of different religious/nonreligious groups (i.e., agnostics, atheists, Protestants, Muslims, Mormons, and Seventh-day Adventists). I included Mormons and Seventh-day Adventists in order to compare stereotypes of agnostics to other lesser known religious groups.

In order to test for socially-desirable responding, I included a between-subjects variable whereby participants either rated traits according to their personal beliefs about the groups or according to society's views of the groups. I hypothesized that the difference between these conditions would be nonsignificant, given the blatant explicit biases toward nonreligious people that other studies have found (e.g., Franks \& Scherr, 2014; Pew Research Center, 2014).

Compared to all other groups, I predicted that agnostics would be seen as the most tolerant, unpredictable, cowardly, and indecisive. Furthermore, I predicted that atheists and agnostics would be viewed as more untrustworthy, immoral, young, and disloyal compared with all other groups. I also predicted that atheists, agnostics, and Muslims would be rated as less patriotic compared with the other groups. Finally, I hypothesized that Muslims would be rated as the most dangerous compared with all other groups. The results of Study 2 aimed to provide support for the stereotype content that was generated in Study 1.

\subsection{Method}

\subsubsection{Participants}

An a priori $\mathrm{G}^{*}$ Power analysis assuming a small effect size $(f=.1)$ and a power of .80 determined that I should collect usable responses from at least 206 participants. I oversampled in MTurk, knowing that not every participant would complete the entire task. Thus, 331 MTurk participants were compensated \$2.00 USD for participating in this study. The only inclusion criterion was that they had to reside in the United States. I excluded participants with duplicate IP addresses and worker IDs from analysis. Furthermore, I checked longitude and latitude coordinates, and IP addresses to ensure that participants who completed the study outside of the United States were excluded as well. Additionally, participants who completed less than $50 \%$ of the items were excluded. Finally, there were two attention checks and not passing both of them resulted in exclusion. The final sample size was 220 (see Table 3 for a demographic summary of participants).

Table 3

Demographic Breakdown of Study 2 
Gender

Male

Female

Theistic Probability

Score of $<3$ on Dawkin's Scale (atheist)

None

Other

\subsubsection{Procedure}

Participants were presented with 6 groups in a randomized order. These groups included agnostics, atheists, Protestants, Seventh-day Adventists, Mormons, and Muslims. After being provided with a definition for the current group they were about to rate (Please see Appendix 1 for definitions), they were asked to either "Please move the slider to the spot that you think is most representative of XXXX" or "Please move the slider on each scale to the 
spot that you think SOCIETY would consider to be most representative of XXXX." I do not hypothesize a statistically significant difference between these conditions.

Antonyms anchored each scale. For example, participants would place a slider along a 101-point scale that ranged from 0 (immoral) to 100 (moral). There were 10 trait pairs that were presented in a randomized order across all groups: immoral-moral, cowardly-brave, indecisive-decisive, disloyal-loyal, young-old, untrustworthy-trustworthy, unpatriotic-patriotic, dangerous-safe, intolerant-tolerant, and unpredictable-predictable. The first word of each pair of words was the left anchor $(0)$ and the second word was the right anchor (100). Afterwards, participants completed questionnaires to assess their personality styles and political orientation. Finally, participants responded to the same religiosity and demographic questions presented in Study 1.

\subsubsection{Covariates}

Because I am investigating stereotypes and attitudes toward a relatively unexamined group (agnostics), I elected to include several measures to serve as covariates so as to ensure that any effects I obtained were due to the stereotypes people associate with different religious and non-religious groups.

\subsubsection{Attitude-based Political Orientation}

Participants completed the 33-item Attitude-based Political Orientation Scale (ABPO; Burton, 2016) to assess their political orientation. There are three subscales: masculine independence, religious traditionalism, and ethnic separateness. Participants responded on a 7-point scale, ranging from 1(strongly disagree) to 7(strongly agree), their level of agreement with each item (e.g., "Higher taxes [primarily for the wealthy] are necessary to address inequity/injustice in society").

For the present study, the internal consistency was excellent for the masculine independence (Cronbach's $\alpha=.95$ ) and religious traditionalism subscales (Cronbach's $\alpha=.92$ ), and good for the ethnic separateness subscale (Cronbach's $\alpha=.86$ ). Appropriate items were reverse-scored, so that higher scores indicated higher levels of masculine independence, religious traditionalism, and ethnic separateness. The average of 18 items gives a masculine independence score $(M=3.12 ; S D=1.35)$; the average of eight items gives a religious traditionalism score $(M=3.12 ; S D=1.58)$; and the average of seven items gives an ethnic separateness score $(M=2.96 ; S D=$ 1.33). The three attitude-based political orientation subscales were included as covariates in the model because ethnic separateness predicts modern racism and masculine independence predicts social dominance (Burton, 2016). Thus, political orientation measured in this way may affect ratings of the various groups.

\subsubsection{Personality}

Participants completed the 10-item Personality Inventory (TIPI; Gosling, Rentfrow, \& Swann Jr., 2003) to assess their level of openness, conscientiousness, and agreeableness. Participants responded on a 7-point scale, ranging 
from 1(strongly disagree) to 7(strongly agree), their level of agreement with each item (e.g., "I see myself as reserved, quiet).

For the present study, the internal consistency was questionable for conscientiousness (Cronbach's $\alpha=.66$ ), unacceptable for agreeableness (Cronbach's $\alpha=.37$ ), and poor for openness (Cronbach's $\alpha=.52$ ). However, this is likely due to each subscale being comprised of only two items. The average of two items gives a conscientiousness score $(M=5.36 ; S D=1.30)$, an agreeableness score $(M=5.47 ; S D=1.15)$, and openness score $(M=5.09 ; S D=$ 1.27). Personality variables were included as covariates in the model because individuals who are very low in agreeableness, very low in openness, and very high in conscientiousness may view outgroup members as more threatening (Sibley \& Duckett, 2008).

\subsubsection{Orderliness}

Participants completed the 10-item Orderliness subscale from the Big-Five Aspects Scale (DeYoung, Quilty, \& Peterson, 2007) to assess their level of orderliness. Participants responded on a 7-point scale, ranging from 1(never or very rarely true) to 7(very often or always true), their level of agreement with each item (e.g., "I follow a schedule"). For the present study, the average of the 10 items gave an overall orderliness score $(M=4.73 ; S D=$ 1.13 ) and the internal consistency was good (Cronbach's $\alpha=.87$ ). Orderliness was included as a covariate in the model because individuals high on orderliness are more likely to prefer structure and predictability; outgroup members may be seen to threaten these preferences.

\subsubsection{Progressivism}

Participants completed the 32-item Moral Foundations Questionnaire (Graham et al., 2011; Haidt \& Graham, 2007) to assess which moral foundations (harm, fairness, purity, ingroup, and authority) they deem as most important. For Part 1, participants responded on a 7-point scale, ranging from 1(not at all relevant) to 7(extremely relevant), to indicate the extent to which they take certain factors into consideration when judging right from wrong (e.g., "Whether or not someone suffered emotionally"). For Part 2, participants responded on a 7-point scale, ranging from 1(strongly disagree) to 7(strongly agree), their level of agreement with each item (e.g., "I am proud of my country's history").

A score for Harm $(M=5.20 ; S D=1.05)$, Authority $(M=4.12 ; S D=1.30)$, Purity $(M=3.73 ; S D=1.72)$, Fairness $(M=5.13 ; S D=0.99)$, and Ingroup $(M=3.79 ; S D=1.31)$ was calculated by averaging the appropriate items for each subscale. For the present study, the internal consistency was acceptable for harm (Cronbach's $\alpha=.74$ ); questionable for fairness (Cronbach's $\alpha=.68$ ); good for ingroup (Cronbach's $\alpha=.83$ ); good for authority (Cronbach's $\alpha=.81$ ); and excellent for purity (Cronbach's $\alpha=.90$ ).

A Progressivism score $(M=1.29 ; S D=1.51)$ was calculated by summing the ingroup, authority, and purity subscales and subtracting the resulting number from the sum of the fairness and harm subscales. Higher scores 
indicate higher progressivism. Religious moral values focus more heavily on the Binding foundations (ingroup, authority, and purity) compared to secular moral values (Graham \& Haidt, 2010). Previous research suggests that endorsement in the Binding foundations is more strongly associated with anti-atheist prejudice than endorsement in the Individualizing foundations (fairness and harm; Simpson, Piazza, \& Rios, 2016). Therefore, progressivism was included as a covariate in the model because individual differences on progressivism may be associated with level of acceptance toward outgroup religious/nonreligious groups.

\subsubsection{Familiarity}

Participants responded on a 101-point sliding scale, ranging from 0(very unfamiliar) to 100(very familiar), their level of familiarity with each of the six groups. Familiarity is included as a covariate to ensure that certain traits are not viewed as representative of a group due to unfamiliarity. Higher scores indicate greater familiarity with the group. Familiarity was included as a covariate in the model.

\subsubsection{Theistic Probability}

Participants completed an adapted version of the 1-item spectrum of theistic probability scale to assess their belief in a deity (Dawkins, 2006). To identify their belief in a deity, participants rated on a 7-point scale, ranging from 1(" $I$ am $100 \%$ sure that God does not exist") to 7(I am 100\% sure that God exists") their certainty in God's existence. Thus, higher scores indicate a stronger belief in God. Theistic probability was included for demographic purposes.

\subsubsection{Data Analysis}

I conducted statistical analyses in R (Version 3.5.0). Using the lmer function from the lme4 package (Bates et al., 2018), I conducted a two-level multilevel model (MLM) because each participant reported the representativeness of 10 trait pairs across six groups. The representativeness of each trait was modelled as a function of the various religious groups. For model 1, five contrasts were created; For model 2, another five contrasts were created (see Table 4 for contrasts). The three subscales of the ABPO (religious traditionalism, ethnic separateness, and masculine independence), orderliness, progressivism, and the between-subjects variable (personal beliefs vs. society), familiarity, conscientiousness, openness, and agreeableness were included as covariates in both models.

Table 4

Contrasts for the MLM Models

Contrasts Comparison

Model 1 


$\begin{array}{ll}\text { C1 } & \text { Agnostic-Atheist } \\ \text { C2 } & \text { Agnostic-Protestant } \\ \text { C3 } & \text { Agnostic-Mormon } \\ \text { C4 } & \text { Agnostic-Seventh Day Adventist } \\ \text { C5 } & \text { Atheist-Muslim }\end{array}$

Model 2

C6

Agnostic-Muslim

C7

Atheist-Seventh Day Adventist

C8

Protestant-Atheist

C9

Protestant-Muslim

C10 Seventh Day Adventist-Mormon

Because the intraclass correlation coefficients (ICCs) for nine of the 10 models were greater than 0.10 , this justifies the use of MLM. The ICC was .16 for the morality model, .15 for tolerance, .22 for loyalty, .15 for predictability, .25 for bravery, .17 for decisiveness, .22 for trustworthiness, .16 for danger, and .21 for patriotism. The only ICC that was less than .10 was for age, where the ICC was .07.

Lastly, I included Mormons and Seventh-day Adventists in this study in order to have a Christian comparison group that participants may as equally unfamiliar with as agnostics. After computing familiarity scores, Mormons $(M=$ $50.82)$ were more comparable to agnostics $(M=65.38)$ than Seventh-day Adventists $(M=36.47)$. Therefore, for simplicity's sake, I do not report comparisons that include Seventh-day Adventists (i.e., C4, C7, or C10).

\subsection{Results}

Because I computed two models for each of the 10 traits, my alpha-level was Bonferroni-adjusted to $\alpha=.05 / 20=$ .0025. For all of the following results, I controlled for religious traditionalism, ethnic separateness, masculine independence, orderliness, conscientiousness, agreeableness, openness, familiarity, and the personal vs. society 
condition in the models. Therefore, all of the following reported results are significant above and beyond any associations the covariates have with the dependent variables.

\subsubsection{Age}

Agnostics were rated as significantly older than atheists, $b=31.63, S E=2.64, t(1064)=11.99, p<.001, r_{p b}=.09$ (see Table 5 for descriptives). However, agnostics were rated as significantly younger than Protestants, $b=-26.09$, $S E=2.14, t(1093)=-12.20, p<.001, r_{p b}=-.62$ and Mormons, $b=-16.16, S E=2.10, t(1070)=-7.69, p<.001, r_{p b}=$ -.52 . There was no statistically significant difference between agnostics and Muslims, $b=5.54, S E=2.86, t(1088)=$ $-1.94, p=.053, r_{p b}=-.40$.

There was no statistically significant difference between the atheist and Muslim condition, $b=5.54, S E=2.86$, $t(1088)=1.94, p=.053, r_{p b}=-.45$. However, atheists were rated as younger than Protestants, $b=103.80, S E=$ $6.68, t(1132)=15.55, p<.001, r_{p b}=.64$. Finally, Protestants were rates as older than Muslims, $b=-43.61, S E=$ $4.94, t(1143)=-8.84, p<.001, r_{p b}=.31$.

The main effect of the between-subjects variable (personal views vs. societal views) did not reach significance, $b=$ $1.217, S E=0.638, t(200)=1.908, p=.058, r_{p b}=.07$.

Table 5

Descriptives for Age, Bravery, and Danger

\begin{tabular}{llll}
\hline Group & Age & Bravery & Danger \\
\hline Atheist & 35.94 & 52.55 & 53.20 \\
& $(21.66)$ & $(26.87)$ & $(27.63)$ \\
Agnostic & 39.60 & 54.16 & 61.34 \\
& $(19.66)$ & $(22.18)$ & $(23.72)$ \\
Muslim & 56.06 & 49.00 & 40.06 \\
& $(18.41)$ & $(25.14)$ & $(27.97)$ \\
Mormon & 62.12 & 56.29 & 65.97 \\
Seventh-day Adventist & $(17.53)$ & $(19.82)$ & $(21.75)$ \\
& 63.22 & 58.25 & 65.47
\end{tabular}


Note. SD is in parentheses.

\subsubsection{Bravery}

Agnostics were rated as braver than atheists, $b=19.72, S E=2.89, t(1074)=6.83, p<.001, r_{p b}=.03$ and Muslims, $b$ $=10.46, S E=3.13, t(1092)=3.34, p<.001, r_{p b}=.11$ (see Table 5 for descriptives). However, agnostics were rated as less brave than Protestants, $b=-9.26, S E=2.34, t(1094)=-3.96, p<.001, r_{p b}=-.20$. The difference between the agnostic and Mormon conditions was nonsignificant, $b=-3.60, S E=2.29, t(1077)=-1.57, p=.117, r_{p b}=-.05$.

Protestants were rated as more brave than atheists, $b=43.45, S E=7.35, t(1125)=5.91, p<.001, r_{p b}=.21$ and Muslims, $b=-17.65, S E=5.44, t(1134)=-3.25, p<.001, r_{p b}=.29$. Finally, atheists were rated as braver than Muslims, $b=9.35, S E=2.31, t(1085)=4.05, p<.001, r_{p b}=.07$.

The main effect of the between-subjects variable was significant, such that participants who reported personal views, compared with societal views, were more likely to report higher scores on bravery, $b=3.15, S E=0.88, t(208)=$ $3.57, p<.001, r_{p b}=.15$.

\subsubsection{Danger}

Agnostics were rated as safer than atheists, $b=52.82, S E=3.26, t(1075)=16.19, p<.001, r_{p b}=.16$, and Muslims, $b$ $=34.08, S E=3.54, t(1095)=9.63, p<.001, r_{p b}=.38$ (see Table 5 for descriptives). However, agnostics were rated as less safe than Protestants, $b=-18.75, S E=2.65, t(1099)=-7.08, p<.001, r_{p b}=-.22$, and Mormons, $b=-14.78$, $S E=2.60, t(1080)=-5.69, p<.001, r_{p b}=-.10$.

Muslims were rated as more dangerous than atheists, $b=35.44, S E=2.62, t(1088)=13.55, p<.001, r_{p b}=.23$, and Protestants, $b=-32.64, S E=6.14, t(1142)=-5.32, p<.001, r_{p b}=.53$. Finally, atheists were rated less safe than Protestants, $b=85.39, S E=8.30, t(1133)=10.29, p=.001, r_{p b}=.35$.

The main effect of the between-subjects variable was significant, such that participants who reported personal views, compared with societal views, were more likely to report lower scores on danger, $b=3.42, S E=0.91, t(208)=3.76$, $p<.001, r_{p b}=.14$. 


\subsubsection{Decisiveness}

The difference between the agnostic and atheist conditions was nonsignificant, $b=-4.64, S E=3.26, t(1066)=-1.42$, $p=.155, r_{p b}=-.27$ (see Table 6 for descriptives). Agnostics were rated as less decisive than Protestants, $b=-10.86$, $S E=2.64, t(1090)=-4.11, p<.001, r_{p b}=-.44$, Mormons, $b=-8.74, S E=2.59, t(1070)=-3.38, p<.001, r_{p b}=-.38$, and Muslims, $b=-15.50, S E=3.53, t(1084)=-4.39, p<.001, r_{p b}=-.36$.

Atheists were rated as less decisive than Muslims, $b=-9.86, S E=2.61, t(1080)=-3.78, p<.001, r_{p b}=-.09$ and Protestants, $b=46.84, S E=8.28, t(1120)=5.65, p<.001, r_{p b}=.17$. Finally, with the Bonferroni adjustment, the difference between the Muslim and Protestant conditions was nonsignificant, $b=-15.17, S E=6.13, t(1130)=-2.48$, $p=.013, r_{p b}=.08$.

With the Bonferroni-adjustment, the main effect of the between-subjects variable (personal views vs. societal views) did not reach significance, $b=2.29, S E=.918, t(207)=2.49, p=.013, r_{p b}=.09$.

Table 6

Descriptives for Decisiveness, Loyalty, and Morality

\begin{tabular}{|c|c|c|c|}
\hline Group & Decisiveness & Loyalty & Morality \\
\hline \multirow[t]{2}{*}{ Atheist } & 60.85 & 48.00 & 46.63 \\
\hline & $(27.63)$ & $(26.31)$ & $(25.99)$ \\
\hline \multirow[t]{2}{*}{ Agnostic } & 45.27 & 54.92 & 55.61 \\
\hline & $(23.72)$ & $(23.24)$ & $(20.65)$ \\
\hline \multirow[t]{2}{*}{ Muslim } & 65.63 & 57.20 & 48.48 \\
\hline & $(27.97)$ & $(28.17)$ & (29.17) \\
\hline \multirow[t]{2}{*}{ Mormon } & 65.74 & 69.11 & 63.52 \\
\hline & $(21.75)$ & $(20.42)$ & $(21.22)$ \\
\hline \multirow[t]{2}{*}{ Seventh-day Adventist } & 65.38 & 66.21 & 65.98 \\
\hline & (21.14) & $(20.33)$ & $(20.43)$ \\
\hline Protestant & 68.98 & 69.84 & 71.98 \\
\hline
\end{tabular}


Note. SD is in parentheses.

\subsubsection{Loyalty}

Agnostics were rated as more loyal than atheists, $b=33.91, S E=3.08, t(1068)=11.01, p<.001, r_{p b}=.14$ (see Table 6 for descriptives). However, agnostics were rated as less loyal than Protestants, $b=-14.01, S E=2.50$, $t(1089)=-5.61, p<.001, r_{p b}=-.33$, Mormons, $b=-17.85, S E=2.45, t(1072)=-7.28, p<.001, r_{p b}=-.31$, and Muslims, $b=15.08, S E=3.33, t(1071)=4.53, p=<.001, r_{p b}=-.04$.

Protestants were rated as more loyal than atheists, $b=98.49, S E=7.83, t(1118)=12.58, p<.001, r_{p b}=.43$ and Muslims, $b=-49.96, S E=5.79, t(1127)=-8.63, p<.001, r_{p b}=.25$. There was no statistically significant difference between the atheist and Muslim condition, $b=4.46, S E=2.47, t(1080)=1.81, p=.071, r_{p b}=-.17$.

The main effect of the between-subjects variable was significant, such that participants who reported personal views, compared with societal views, were more likely to report higher scores on loyalty, $b=3.14, S E=0.95, t(207)=$ $3.32, p=.001, r_{p b}=.14$.

\subsubsection{Morality}

Agnostics were rated as significantly more moral than atheists, $b=45.68, S E=3.29, t(1074)=13.87, p<.001, r_{p b}=$ .16 and Muslims, $b=23.89, S E=3.57, t(1093)=6.69, p<.001, r_{p b}=.14$ (see Table 6 for descriptives). In contrast, agnostics were rated as significantly less moral than Protestants, $b=-21.79, S E=2.67, t(1098)=-8.15, p<.001, r_{p b}$ $=-.33$ and Mormons, $b=-11.56, S E=2.61, t(1077)=-4.428, p<.001, r_{p b}=-.17$.

Atheists were rated as less moral than Muslims, $b=17.00 S E=2.64, t(1087)=6.45, p<.001, r_{p b}=-.03$ and Protestants, $b=95.15, S E=8.35, t(1132)=11.39, p<.001, r_{p b}=-.45$. Finally, Muslims were rated as significantly less moral than Protestants, $b=-40.12, S E=6.18, t(1142)=-6.49, p<.001, r_{p b}=-.45$.

The main effect of the between-subjects variable was significant, such that participants who reported personal views, compared with societal views, were more likely to report higher scores on morality, $b=3.46, S E=.90, t(207)=$ $3.83, p<.001, r_{p b}=.14$.

\subsubsection{Patriotism}

Agnostics were rated as more patriotic than atheists, $b=48.89, S E=2.97, t(1074)=16.45, p<.001, r_{p b}=.13$, and Muslims, $b=23.08, S E=3.22, t(1091)=7.16, p<.001, r_{p b}=.25$ (see Table 7 for descriptives). However, agnostics were rated as less patriotic than Protestants, $b=-25.81, S E=2.41, t(1094)=-10.71, p<.001, r_{p b}=-.39$, and Mormons, $b=-15.40, S E=2.35, t(1077)=-6.54, p<.001, r_{p b}=-.21$. 
Muslims were viewed as less patriotic than atheists, $b=27.51, S E=2.38, t(1085)=11.56, p<.001, r_{p b}=.13$, and Protestants, $b=-26.87, S E=5.60, t(1132)=-4.80, p<.001, r_{p b}=.54$. Finally, atheists were rated as less patriotic than Protestants, $b=83.98, S E=7.57, t(1123)=11.10, p=.001, r_{p b}=.47$.

Table 7

Descriptives for Patriotism, Predictability, and Tolerance

\begin{tabular}{|c|c|c|c|}
\hline Group & Patriotism & Predictability & Tolerance \\
\hline \multirow[t]{2}{*}{ Atheist } & 47.36 & 49.22 & 50.75 \\
\hline & $(25.22)$ & $(27.20)$ & $(29.85)$ \\
\hline \multirow[t]{2}{*}{ Agnostic } & 53.56 & 50.15 & 62.30 \\
\hline & $(22.75)$ & $(22.92)$ & (26.33) \\
\hline \multirow[t]{2}{*}{ Muslim } & 40.52 & 41.02 & 34.39 \\
\hline & $(28.30)$ & $(26.73)$ & $(25.88)$ \\
\hline \multirow[t]{2}{*}{ Mormon } & 62.72 & 66.37 & 47.98 \\
\hline & (19.07) & $(22.40)$ & $(24.35)$ \\
\hline \multirow[t]{2}{*}{ Seventh-day Adventist } & 60.48 & 62.82 & 51.29 \\
\hline & $(21.26)$ & $(22.08)$ & $(22.82)$ \\
\hline \multirow[t]{2}{*}{ Protestant } & 71.14 & 70.60 & 56.53 \\
\hline & $(19.30)$ & (19.23) & $(24.33)$ \\
\hline
\end{tabular}

Note. SD is in parentheses.

The main effect of the between-subjects variable was significant, such that participants who reported personal views, compared with societal views, were more likely to report higher scores on patriotism, $b=3.22, S E=.93, t(208)=$ $3.45, p<.001, r_{p b}=.13$.

\subsubsection{Predictability}

Agnostics were rated as more predictable than atheists, $b=47.06, S E=3.24, t(1068)=14.54, p<.001, r_{p b}=.02$ and Muslims, $b=23.38, S E=3.51, t(1089)=6.66, p<.001, r_{p b}=.18$ (see Table 7 for descriptives). However, agnostics 
were rated as less predictable than Protestants, $b=-23.68, S E=2.63, t(1096)=-8.99, p<.001, r_{p b}=-.44$ and Mormons, $b=-21.02, S E=2.57, t(1072)=-8.18, p<.001, r_{p b}=-.34$.

Muslims were rated as less predictable than atheists, $b=27.98, S E=2.59, t(1083)=10.79, p<.001, r_{p b}=.15$ and Protestants, $b=-35.67, S E=6.09, t(1138)=-5.86, p<.001, r_{p b}=.54$. Finally, atheists were rated less predictable than Protestants, $b=99.62, S E=8.23, t(1126)=12.11, p<.001, r_{p b}=.41$. See Table 7 for descriptives.

The main effect of the between-subjects variable was significant, such that participants who reported personal views, compared with societal views, were more likely to report higher scores on predictability, $b=2.78, S E=.88, t(206)=$ $3.18, p=.002, r_{p b}=.11$.

\subsubsection{Tolerance}

Agnostics were rated as more tolerant than atheists, $b=33.34, S E=3.54, t(1071)=9.42, p<.001, r_{p b}=.20$ and Muslims, $b=26.94, S E=3.83, t(1092)=7.03, p<.001, r_{p b}=.47$ (see Table 7 for descriptives). With the Bonferroni adjustment, the difference between agnostics and Protestants was nonsignificant, $b=-6.40, S E=2.86, t(1096)=$ 2.23, $p=.026, r_{p b}=0.11$. Additionally, the difference between agnostics and Mormons was nonsignificant, $b=2.81$, $S E=2.81, t(1076)=.999, p=.318, r_{p b}=.27$.

Atheists were rated as more tolerant than Muslims, $b=28.30, S E=2.83, t(1085)=10.00, p<.001, r_{p b}=.28$. The difference between the Protestant and Muslim condition was nonsignificant, $b=-5.74, S E=6.63, t(1143)=-0.87, p$ $=.386, r_{p b}=.40$. Finally, with the Bonferroni adjustment, the atheist and Protestant condition was nonsignificant, $b$ $=19.25, S E=8.97, t(1133)=2.15, p=.032, r_{p b}=.11$. See Table 7 for descriptives.

With the Bonferroni-adjustment, the main effect of the between-subjects variable (personal views vs. societal views) did not reach significance, $b=2.60, S E=.92, t(205)=2.83, p=.005, r_{p b}=.11$.

\subsubsection{Trustworthiness}

Agnostics were rated as more trustworthy than atheists, $b=40.42, S E=3.13, t(1074)=12.92, p<.001, r_{p b}=.12$. and Muslims, $b=22.48, S E=3.39, t(1091)=6.62, p<.001, r_{p b}=.27$ (see Table 8 for descriptives). However, agnostics were rated as less trustworthy than Protestants, $b=-17.93, S E=2.54, t(1095)=-7.07, p<.001, r_{p b}=-.24$, and Mormons, $b=-7.98, S E=2.48, t(1077)=-3.21, p=.001, r_{p b}=-.05$.

Muslims were viewed as less trustworthy than atheists, $b=23.74, S E=2.51, t(1086)=9.473, p<.001, r_{p b}=.14$, and Protestants, $b=-23.33, S E=5.89, t(1133)=-3.96, p<.001, r_{p b}=.47$. Finally, atheists were rated as less trustworthy than Protestants, $b=65.86, S E=7.96, t(1124)=8.28, p<.001, r_{p b}=.34$. 
The main effect of the between-subjects variable was significant, such that participants who reported personal views, compared with societal views, were more likely to report higher scores on trustworthiness, $b=3.24, S E=.96, t(208)$ $=3.39, p<.001, r_{p b}=.14$.

Table 8

Descriptives for Trustworthiness and Familiarity

\begin{tabular}{|c|c|c|}
\hline Group & Trustworthiness & Familiarity \\
\hline \multirow[t]{2}{*}{ Atheist } & 50.91 & 68.06 \\
\hline & $(27.78)$ & $(30.17)$ \\
\hline \multirow[t]{2}{*}{ Agnostic } & 57.39 & 65.38 \\
\hline & $(24.65)$ & (30.14) \\
\hline \multirow[t]{2}{*}{ Muslim } & 42.97 & 46.68 \\
\hline & $(27.05)$ & $(28.06)$ \\
\hline \multirow[t]{2}{*}{ Mormon } & 59.73 & 50.82 \\
\hline & $(22.11)$ & $(26.78)$ \\
\hline \multirow[t]{2}{*}{ Seventh-day Adventist } & 61.08 & 36.47 \\
\hline & $(21.52)$ & (27.66) \\
\hline \multirow[t]{2}{*}{ Protestant } & 68.32 & 68.58 \\
\hline & (20.03) & $(25.56)$ \\
\hline
\end{tabular}

Note. SD is in parentheses.

\subsubsection{Familiarity}

This model was ran without covariates. Results indicated participants were less familiar with agnostics than Protestants, $b=-25.15, S E=2.87, t(1078)=-8.77, p<.001, r_{p b}=.06$ (see Table 8 for descriptives). However, they were more familiar with agnostics than Mormons, $b=10.37, S E=2.87, t(1078)=3.62, p<.001, r_{p b}=-.25$ and Muslims $b=-30.62, S E=3.85, t(1078)=-7.95, p<.001, r_{p b}=-.31$. Finally, the difference between the agnostic and atheist condition was nonsignificant, $b=-5.46, S E=3.63, t(1078)=-1.51, p<.132, r_{p b}=.04$. 


\subsection{Discussion}

In Study 2, participants rated how representative 10 trait pairs were of various religious and nonreligious groups Study 2 supported some of the qualitative results of Study 1 and my hypotheses, but did not support others. It is important to note that I do not consider effect sizes of $r_{p b}<.1$ to be pragmatically significant in the discussion of my results.

\subsubsection{Age}

In line with my hypotheses, atheists and agnostics were rated as younger than Protestants and Mormons. These perceptions are consistent with Cragun et al. (2012), who found that nonreligious individuals are, on average, younger than religious individuals. A number of explanations could explain these findings. Firstly, the nonreligious could be a group expected to rise in prevalence over the coming years. If this is the case, then nonreligiosity is likely viewed as a stable trait. Alternatively, nonreligious views may be an act of rebellion against older generations that will wear off over time. If this is the case, then nonreligiosity is likely viewed as an unstable trait. Finally, the teenage years and emerging adulthood is a period of identity formation and agnosticism may be viewed as transitional state that occurs until individuals decide what they believe in. This latter explanation explains Study 1's findings, where agnostics, but not atheists, were rated as younger than Christians and Muslims. However, it does not explain Study 2's findings, where both atheists and agnostics were rated as younger than Christian denominations. Unexpectedly, there was no difference in age ratings between Muslims and the nonreligious groups. Future research should investigate whether young age stereotypes feed into prejudice and discrimination toward nonreligious individuals.

\subsubsection{Bravery}

I hypothesized agnostics to be rated the most cowardly compared with all other groups. Contrary to my prediction, agnostics only rated as less brave than Protestants. These findings are also generally supported by Study 1, which suggested that agnostics are not viewed as more cowardly than atheists, Christians, or Muslims. Therefore, these findings suggest that individuals do not believe agnostics refusal to side with theists or atheists is driven by fear of commitment to one side. Follow-up analyses indicated that bravery correlated .73 with morality, .76 with trustworthiness, and .53 with decisiveness. Therefore, these findings also suggest that decisiveness appears to be less important to perceptions of bravery compared with how closely the group is associated with perceptions of morality and trustworthiness.

\subsubsection{Danger}

As predicted and consistent with Study 1, Muslims were rated as the most dangerous group. They were also the only group whose mean was located on the dangerous compared with safe end of the continuum. Also, not surprisingly, agnostics were rated as safer than atheists and Muslims, but less safe than Mormons and Protestants. These findings 
suggest that agnostics and atheists diverge on perceptions of safety. Therefore, agnostics appear to be at an advantage over atheists and Muslims regarding safety concerns and, therefore, are seemingly less likely to be discriminated against due to perceptions of being dangerous.

\subsubsection{Decisiveness}

As expected, agnostics were rated as less decisive than Protestants, Mormons, and Muslims. However, contrary to my hypothesis and Study 1's results, agnostics were not rated less decisive than atheists, although means were in the hypothesized direction. This latter finding is particularly surprising because indecisiveness was the most common stereotype for agnostics, with 44 participants reporting them as such in Study 1. In contrast, only 1 participant rated atheists as indecisive in Study 1. Further research is needed in order to determine why the results of Study 1 and 2 diverge regarding decisiveness.

\subsubsection{Loyalty}

As expected, agnostics were rated as less loyal than Protestants and Mormons. Also, as expected, atheists were rated as less loyal than Protestants. Unexpectedly, agnostics and atheists were not rated as less loyal than Muslims. Finally, agnostics were rated as more loyal than atheists.

These findings suggest that agnostics' refusal to side with theists or atheists, does not cause them to be perceived as any less loyal than atheists, who have committed to a side. Rather, it appears that belief in Christianity drives perceptions of loyalty. Therefore, in contexts where loyalty is important, such as in politics and situations where cooperation is vital for the benefit of all, atheists, agnostics, and Muslims are likely to be at a disadvantage compared with Christian denominations. Future research should investigate whether the small effect size between atheists and agnostics on ratings of loyalty results in differing levels of discrimination between the two groups.

\subsubsection{Morality}

As expected and consistent with Study 1's results, nonreligious groups were rated less moral than Christian groups. Also consistent with Study 1, agnostics were rated as more moral than atheists. Unexpectedly, agnostics were rated as more moral than Muslims. Thus, experiences of discrimination related to morality may differ between atheists and agnostics, with atheists and Muslims, rather than the nonreligious, being at the greatest disadvantage compared with other groups. Similar to differences in perceptions of loyalty, future research will need to investigate whether these small effect sizes translate to different experiences of discrimination.

\subsubsection{Patriotism}

Consistent with my hypotheses, atheists, agnostics, and Muslims were rated as the least patriotic groups, suggesting others do not view them as supporting American values and the country to the same degree as Christian 
denominations. These perceptions may be associated with viewing atheists, agnostics, and Muslims as unAmerican and threatening the status quo. Further research should investigate whether the small effect size between patriotism ratings of agnostics and atheists translates into different experiences of discrimination severity.

\subsubsection{Predictability}

Regarding predictability, I hypothesized that agnostics would be viewed the least predictable compared with all other groups because they do not deny theists nor atheists viewpoints. Therefore, it may be harder to predict how an agnostic would behave across different contexts. Unexpectedly, agnostics were viewed as more predictable than Muslims and pragmatically no less predictable than atheists. Follow-up analyses indicated that predictability correlated .67 with morality, .68 with danger, 68 with trustworthiness, and .46 with decisiveness. Therefore, it appears perceptions of predictability are more closely tied to perceptions of morality, danger, and trustworthiness than with indecisiveness or fence-sitting.

\subsubsection{Tolerance}

I hypothesized that agnostics would be rated the most tolerant compared with all other groups because they do not deny theists' or atheists' views. As predicted, agnostics were rated as more tolerant than atheists and Muslims. Unexpectedly, they were not rated as more tolerant than Protestants or Mormons; however, a p-value of .026 for the agnostic/Protestant comparison warrants further investigation.

\subsubsection{Trustworthiness}

As predicted, atheists and agnostics were rated as less trustworthy than Protestants and Mormons. Unexpectedly, Muslims were considered the least trustworthy of all groups. Finally, agnostics were rated as more trustworthy than atheists; however, future research will have to examine whether this small effect size translates into different experiences in discrimination.

\subsubsection{Familiarity}

Because individuals reported being more familiar with agnostics than with Mormons and Muslims, and because stereotype content differed between agnostics and these two groups, it appears that stereotype content of agnostics is not driven by lack of familiarity with the group. Additionally, these findings suggest that perceptions of indecisiveness are not due to individuals being unclear on what defines an agnostic or what values agnostics hold.

\subsubsection{Personal Views Versus Societal Views}

Unexpectedly, individuals in the personal views, compared with societal views, condition were more likely to give positive ratings of bravery, safety, loyalty, morality, patriotism, and trustworthiness to the groups they were rating. 
All of these differences were associated with a small effect size. As predicted, there were no differences in perceptions of age, decisiveness, predictability, or tolerance between the two conditions. This demonstrates that people are 1) less likely to report their own explicit biases when it is linked to personal beliefs compared to societal and/or 2) believe that society holds more explicit biases than themselves, known as the better-than-average bias or the bias blind spot (Pronin, Lin, Ross, 2002).

Studies 1 and 2 established the content of stereotypes of agnostics and contrasted that stereotype with both nonreligious (atheists) and religious (Christians, Protestants, Mormons, Muslims) groups. For Study 3 I aimed to determine how two of the stereotypes of agnostics, namely immorality and indecisiveness, influence religious/nonreligious categorization of individuals. 


\section{Chapter 4 Study 3}

\subsection{General Method}

The methods and procedure of Study 3 were adapted from Gervais et al. (2011) and Gervais (2014). As such, I relied on the representativeness heuristic to determine people's inclinations to associate agnostics with various stereotypes. Tversky and Kahneman (1983) demonstrated the representative heuristic by describing Bill, who is intelligent and good at math, but unimaginative and weak in humanities. When asked if Bill is more likely (a) someone who plays jazz for a hobby or (b) an accountant who plays jazz for a hobby, individuals are likely to make a conjunction error mistake and believe that option (b) is more plausible. The reason that option (b) is an error is because option (b) is a subset of option (a); statistically, it is less likely for two constituents to occur together than it is for only one of the constituents to occur. Individuals are more likely to make this mistake when they believe that the added constituent is representative of the person. Therefore, if option (b) stated that Bill was an artist who plays jazz for a hobby, individuals would be less inclined to choose option (b) over option (a) because option (b) no longer contains information that may be seen as representative of Bill.

In three experiments, I tested people's inclinations to associate immorality and indecisiveness with agnostics. More specifically, Study $3 a$ tested whether agnostics are associated with immorality, Study $3 b$ tested whether agnostics are associated with indecisiveness about moral issues, and Study $3 \mathrm{c}$ tested whether agnostics are associated with indecisiveness in general (i.e., in situations that are unrelated to morality). I tested these associations in three separate studies by presenting participants with a vignette about an individual who was acting immorally (Study 3a), was indecisive on acting morally (Study 3b), or was indecisive on an issue unrelated to morality (Study 3c).

There were four conditions within each study that manipulated the potential religious/non-religious group that the individual could belong to. More specifically, I manipulated whether the individual in the vignette could possibly be someone who believes that there is no God, someone who believes that God's existence is unknown, a Christian, or a Muslim. In study 3a, there were two additional conditions: an atheist condition and an agnostic condition. Having these two additional conditions allowed me to test whether using the labels 'atheist' and 'agnostic' (known as selfidentified atheism and agnosticism) versus using a definition of them without a label (known as theological atheism and agnosticism) affected the number of conjunction errors that participants made.

\subsubsection{Participants}

Based on the smaller effect sizes of Gervais' (2014) Experiments 1-3, I computed an a priori G*Power analysis assuming an odds ratio of 4 and power of .80. The power analysis indicated I need to collect useable data from at least 64 participants (i.e., 32 per cell). I oversampled in MTurk, given not all participants would complete the entire task. 
Two hundred forty-three MTurk participants for Study 3a, 186 MTurk participants for Study 3b and 163 MTurk participants for Study 3c were recruited and received \$1.00 USD for participating in the study. The only inclusion criterion was that they had to reside in the United States. Participants with duplicate IP addresses and worker IDs were excluded from analysis. Furthermore, longitude and latitude coordinates, and IP addresses were checked to ensure that participants who completed the study outside of the United States were excluded as well. Additionally, participants who were familiar with a conjunction fallacy paradigm or who did not respond to the conjunction fallacy item were excluded. The final sample size was 230 for Study 3a, 137 for Study 3b, and 145 for Study 3c (see Table 9 for a demographic summary of participants).

Table 9

Demographic Breakdown of Study 3

\begin{tabular}{|c|c|c|c|}
\hline Demographic Category & Study $3 a$ & Study $3 b$ & Study $3 \mathrm{c}$ \\
\hline Mean age (SD) & $36.35(10.99)$ & $34.52(10.71)$ & $35.97(10.31)$ \\
\hline \multicolumn{4}{|l|}{ Gender $(\%)$} \\
\hline Male & 52 & 54 & 54 \\
\hline Female & 47 & 46 & 46 \\
\hline \multicolumn{4}{|l|}{ Theistic Probability (\%) } \\
\hline Score of $<3$ on Dawkin's Scale (atheist) & 38 & 31 & 38 \\
\hline Score of 3 to 5 on Dawkin's Scale (agnostic) & 28 & 32 & 25 \\
\hline Score of $>5$ on Dawkin's Scale (theist) & 35 & 38 & 37 \\
\hline \multicolumn{4}{|l|}{ Religious Affiliation (\%) } \\
\hline Christian & 40 & 38 & 44 \\
\hline Atheist & 20 & 12 & 16 \\
\hline Agnostic & 17 & 25 & 17 \\
\hline
\end{tabular}




\subsubsection{Data Analysis}

Analyses were conducted in R (Version 3.5.0). Conjunction error was a binary outcome as the participant either made the mistake or they did not; this violated the normality assumption required for traditional regression. Thus, logistic regressions were performed to model conjunction errors. More specifically, I conducted logistic regressions to determine whether making conjunction error mistakes were more likely if the individual in the vignette could possibly be an atheist or agnostic compared to any other group.

\subsection{Study 3a}

Study 3a tested participants' inclinations to associate different religious and non-religious groups with immorality. In line with results from Gervais (2014), I hypothesized that participants would make more conjunction error mistakes when the individual in the vignette could potentially be an atheist compared to any other group. However, extending Gervais' work, I also hypothesized that participants would be more likely to make errors when the individual could potentially be an agnostic as well; however, the effects should not be as strong for agnostics as they are for atheists. Finally, because Gervais (2014) used a definition of atheism in order to attenuate negative knee-jerk reactions to the label 'atheist,' I predicted that using a label, rather than definition, for atheist and agnostic would result in a higher rate of conjunction errors.

\subsubsection{Procedure}

After consenting to participate, participants in all six conditions were presented with the following vignette that is near-identical to Gervais et al. (2011):

Richard is 25 years old. On his way to work one day, he accidentally backed his car into a parked van. Because pedestrians were watching, he got out of his car. He pretended to write down his insurance information. He then tucked the blank note into the van's window before getting back into his car and driving away.

Later the same day, Richard found a wallet on the sidewalk. Nobody was looking, so he took all of the money out of the wallet. He then threw the wallet in a trash can.

Participants then reported whether it was more likely that Richard was (a) a competitive swimmer or (b) a competitive swimmer and XXXX. Depending on which condition participants were in, XXXX was: someone who believes that there is no God, someone who believes that God's existence is unknown, atheist, agnostic, Christian, or 
Muslim. Gervais et al. (2011) used 'teacher' rather than 'competitive swimmer'. The reason I made this change was to have a hobby that I could use across all three studies. Afterwards, participants responded to the same religiosity and demographic questions presented in Study 1.

\subsubsection{Results}

I hypothesized that reading labels for agnostic and atheist, compared with definitions for the groups, would result in greater conjunction error mistakes. Logistic regression determined that there was no statistically significant difference between having the agnostic label provided versus having the definition provided, $b=-0.07, S E=0.45$, $z(78)=-0.16, p=.872, O R=0.93,95 \%$ CI $[0.37,2.27]$. Similarly, there was no statistically significant difference between having the atheist label provided versus having the definition provided, $b=0.35, S E=0.46, z(76)=0.75, p$ $=0.453, O R=1.42,95 \%$ CI $[0.57,3.55]$.

I hypothesized that compared with all other groups, participants would make the most conjunction error mistakes for atheists, followed by agnostics. Unexpectedly, logistic regression determined that there was no statistically significant difference between the agnostic label and atheist label condition, $b=0.27, S E=0.45, z(80)=0.59, p=$ $.558, O R=1.42,95 \% \mathrm{CI}[0.54,3.20]$, nor the agnostic definition and atheist definition condition, $b=-0.16, S E=$ $0.47, z(74)=-0.34, p=.738, O R=0.86,95 \%$ CI $[0.34,2.13]$.

Logistic regression also determined that participants in the agnostic definition and atheist definition conditions were more likely to make a conjunction error compared with participants in the Christian and Muslim conditions. More specifically, participants in the agnostic definition condition were more likely to make conjunction errors compared with those in the Christian condition, $b=1.20, S E=0.53, z(76)=2.26, p=.024, O R=3.32,95 \%$ CI [1.21, 9.92], and those in the Muslim condition, $b=2.05, S E=0.69, z(72)=2.98, p=.003, O R=7.76,95 \%$ CI [2.26, 36.28]. Participants in the atheist definition condition were also more likely to make conjunction error mistakes compared with those in the Christian condition, $b=1.36, S E=0.53, z(75)=2.55, p=.011, O R=3.89,95 \%$ CI [1.42, 11.62], and those in the Muslim condition, $b=2.20, S E=0.69, z(71)=3.20, p=.001, O R=9.07,95 \% \mathrm{CI}[2.64,42.47]$. There was no statistically significant difference between the Christian and Muslim conditions. See Figure 1 and Table 10 for a summary of the results.

Theistic probability beliefs and political orientation were entered into the model as moderators. I effect coded agnostics as the reference group to test whether any interactions existed between proportion of errors and being in the agnostic condition compared with the atheist, Christian, and Muslim condition. Results indicated a significant interaction effect, such that greater belief in a deity was associated with a greater probability of conjunction error for the agnostic condition compared with the Christian condition, $b=-0.85, S E=0.30, z(148)=-2.83, p=.005$. No other interactions were significant for theistic probability or political orientation. 


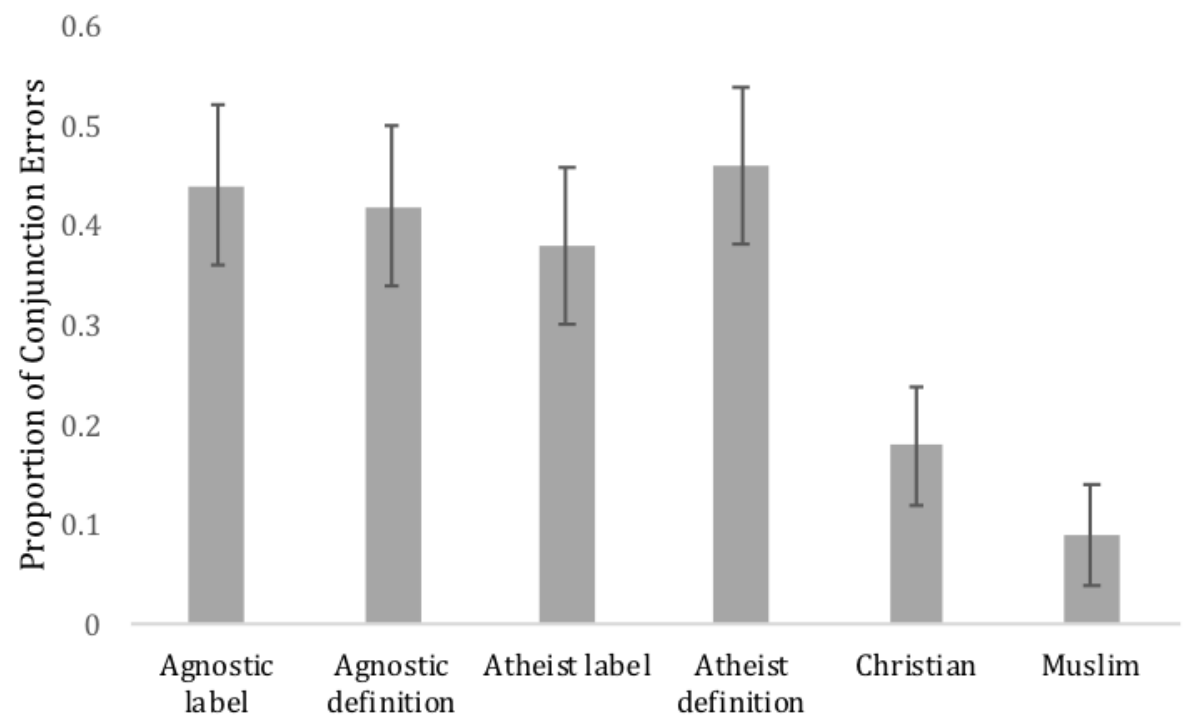

Figure 1. Proportion of conjunction errors as a result of condition when participants read about an individual acting immoral.

Table 10

Study 3 a Odds Ratios Summaries

\begin{tabular}{lcccc}
\hline & Agnostic definition & Atheist definition & Christian & Muslim \\
\hline Agnostic definition & - & 0.86 & $3.32^{*}$ & $7.76^{*}$ \\
Atheist definition & - & - & $3.86^{*}$ & $9.07^{* *}$ \\
Christian & - & - & - & 2.20 \\
Muslim & - & - & - & - \\
\hline
\end{tabular}

$* \mathrm{p}<0.05 ; * * \mathrm{p}<.01 ; * * * \mathrm{p}<.001$

\subsection{Study $3 b$}

Study $3 b$ tested participants' inclinations to associate different religious and non-religious groups with indecisiveness on moral dilemmas. I hypothesized that participants would make more conjunction error mistakes when the individual in the vignette could potentially be an agnostic compared with any other group. However, I also hypothesized that participants would be more likely to make errors when the individual could potentially be an atheist as well; however, the effects should not be as strong for atheists as they are for agnostics. 


\subsubsection{Procedure}

After consenting to participate, participants in all four conditions were presented with the following vignette:

Richard is 25 years old. One day, Richard was walking down the street and noticed a wallet lying on the sidewalk. Richard picked it up and looked at the ID to see if he could return the wallet to the owner. He also noticed the $\$ 60.00$ cash that was in the wallet. Richard stared at the money for quite some time, unable to decide whether he should pocket the money for himself before returning the wallet to the owner.

Participants then reported whether it was more likely that Richard was (a) a competitive swimmer or (b) a competitive swimmer and XXXX. Depending on which condition participants were in, XXXX was: someone who believes that there is no God, someone who believes that God's existence is unknown, Christian, or Muslim. Afterwards, participants responded to the same religiosity and demographic questions presented in Study 1.

\subsubsection{Results}

I hypothesized that participants would make more conjunction error mistakes for the agnostic condition compared with all other groups. Unexpectedly, there were no statistically significant differences between the agnostic and atheist conditions, $b=0.53, S E=0.54, z(67)=0.97, p=.324, O R=1.70,95 \% \mathrm{CI}[0.60,5.01]$, or agnostic and Christian conditions, $b=0.65, S E=0.53, z(70)=1.22, p=.224, O R=1.91,95 \% \mathrm{CI}[0.68,5.59]$. However, individuals in the Muslim condition were significantly less likely to make a conjunction error mistake compared with individuals in the agnostic condition, $b=1.76, S E=0.70, z(69)=2.53, p=.011, O R=5.84,95 \% \mathrm{CI}[1.65$, 27.67]. There were no statistically significant differences between the Muslim and atheist condition, $b=1.24, S E=$ $0.73, z(65)=1.70, p=.090, O R=3.44,95 \%$ CI $[0.89,17.03]$, or the Muslim and Christian condition, $b=-1.12, S E$ $=0.73, z(68)=-1.54, p=.123, O R=0.33,95 \%$ CI $[0.07,1.26]$. See Figure 2 and Table 11 for a summary of the results.

Theistic probability beliefs and political orientation were entered into the model as moderators. I effect coded agnostics as the reference group to test whether any interactions existed between proportion of errors and assignment to the agnostic condition versus the atheist, Christian, and Muslim condition. No interactions reached significance for theistic probability or political orientation. 


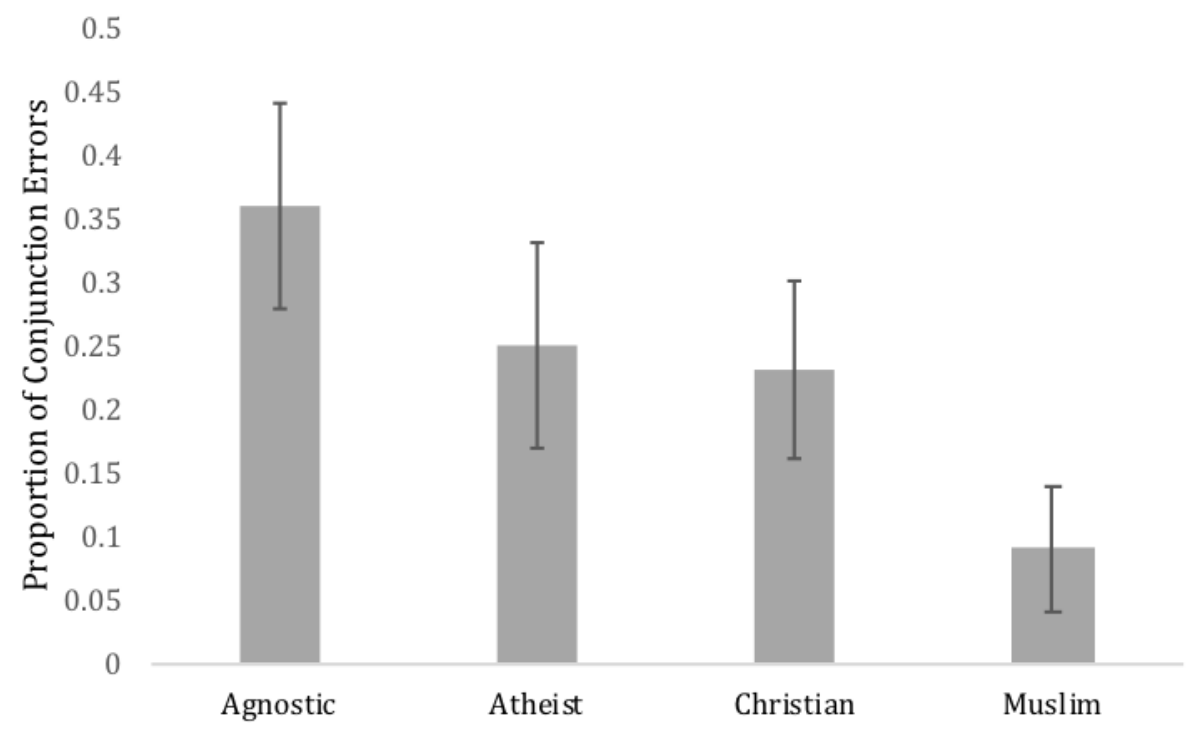

Figure 2. Proportion of conjunction errors as a result of condition when participants read about an individual acting indecisive on morality.

Table 11

Study $3 b$ Odds Ratio Summaries

\begin{tabular}{|c|c|c|c|c|}
\hline & Agnostic definition & Atheist definition & Christian & Muslim \\
\hline $\begin{array}{l}\text { Agnostic } \\
\text { definition }\end{array}$ & - & 1.70 & 1.91 & $5.84 *$ \\
\hline $\begin{array}{l}\text { Atheist } \\
\text { definition }\end{array}$ & - & - & 1.13 & 3.44 \\
\hline Christian & - & - & - & 0.33 \\
\hline Muslim & - & - & - & - \\
\hline
\end{tabular}

$* \mathrm{p}<.05 ; * * \mathrm{p}<.01 ; * * \mathrm{p}<.001$ 


\subsection{Study 3c}

Study $3 \mathrm{c}$ tested participants' inclinations to associate different religious and non-religious groups with indecisiveness in general. I hypothesized that participants would make more conjunction error mistakes when the individual in the vignette could potentially be an agnostic compared with any other group.

\subsubsection{Procedure}

After consenting to participate, participants in all four conditions were presented with the following vignette:

Richard is 25 years old. He has been accepted to his top two choices for graduate school. Although he was notified of his acceptance months ago, he still has not been able to decide on which university he wants to attend. As the accept/decline deadline date approaches, he is still uncertain about which school he will choose.

Participants then reported whether it was more likely that Richard was (a) a competitive swimmer or (b) a competitive swimmer and XXXX. Depending on which condition participants were in, XXXX was: someone who believes that there is no God, someone who believes that God's existence is unknown, Christian, or Muslim. Afterwards, participants responded to the same religiosity and demographic questions presented in Study 1.

\subsubsection{Results}

I hypothesized that participants would make more conjunction error mistakes for the agnostic condition compared with all other groups. Unexpectedly, logistic regression determined that there were no statistically significant differences between the agnostic and atheist condition, $b=0.43, S E=0.64, z(72)=0.68, p=.496, O R=1.54,95 \%$ CI $[0.44,5.73]$, or agnostic and Christian condition, $b=-0.56, S E=0.55, z(72)=-1.01, p=.311, O R=0.57,95 \% \mathrm{CI}$ $[0.19,1.67]$. There was a marginally significant difference between the agnostic and Muslim condition, $b=2.11, S E$ $=1.10, z(70)=1.92, p=.055, O R=8.21,95 \% \mathrm{CI}[1.35,158.15]$. The only significant difference among the groups was between the Christian and Muslim condition, $b=-2.67, S E=1.08, z(71)=-2.48, p=.013, O R=0.07,95 \% \mathrm{CI}$ $[0.00,0.39]$. See Figure 3 and Table 12 for a summary of the results.

Theistic probability beliefs and political orientation were entered into the model as moderators. I effect coded agnostics as the reference group to test whether any interactions existed between proportion of errors and being in the agnostic condition compared with the atheist, Christian, and Muslim condition. Results indicated a significant interaction effect, such that higher conservatism was associated with a greater probability of conjunction error for the agnostic condition compared with the atheist condition, $b=-1.14, S E=0.42, z(144)=-2.70, p=.007$. No other interactions were significant for theistic probability or political orientation. 
0.4

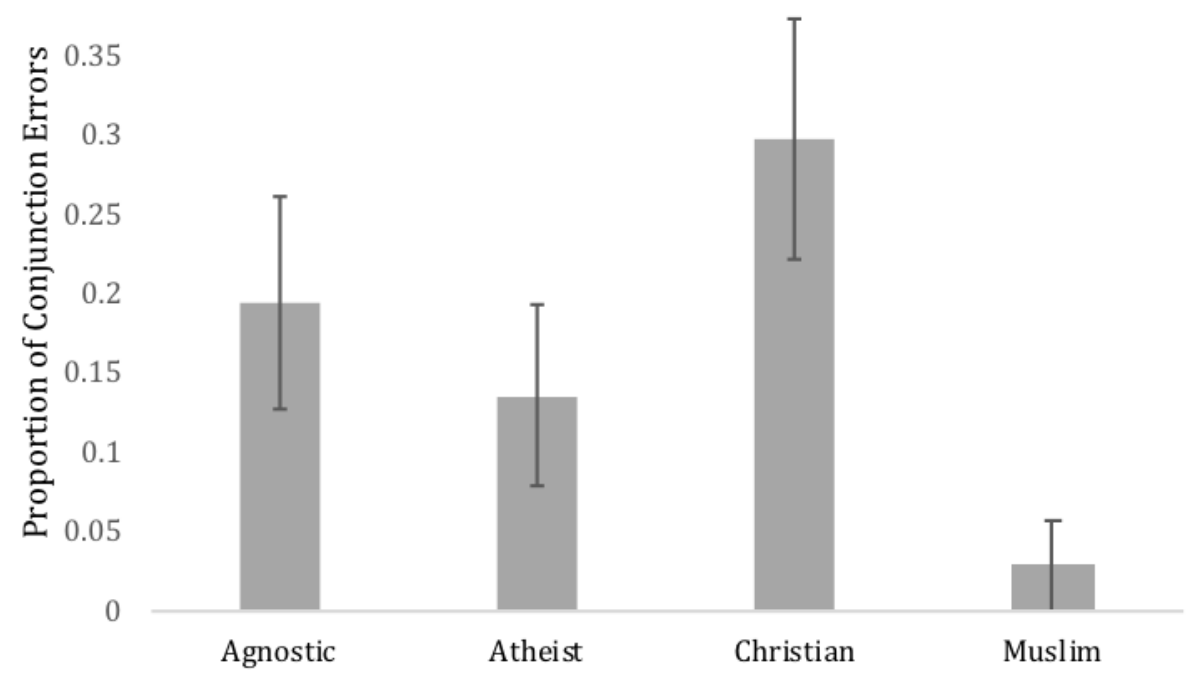

Figure 3. Proportion of conjunction errors as a result of condition when participants read about an individual acting indecisive on an issue unrelated to morality.

Table 12

Study 3c Odds Ratio Summaries

\begin{tabular}{|c|c|c|c|c|}
\hline & Agnostic def & Atheist def & Christian & Muslim \\
\hline Agnostic def & - & 1.54 & 0.57 & 8.21 \\
\hline Atheist def & - & - & 0.37 & 5.31 \\
\hline Christian & - & - & - & $0.06^{*}$ \\
\hline Muslim & - & - & - & - \\
\hline
\end{tabular}

$* \mathrm{p}<.05 ; * * \mathrm{p}<.01 ; * * * \mathrm{p}<.001$

\subsection{Discussion}

Study 3a demonstrated that an immoral act was viewed as more representative of agnostics and atheists compared with Christians and Muslims. Unexpectedly, there was no difference between the atheist and agnostic conditions nor 
between the use of labels or definitions. Study $3 \mathrm{~b}$ demonstrated that an individual struggling with whether to act immorally was seen as more representative of agnostics compared with Muslims, but surprisingly no more representative of agnostics than atheists or Christians. Finally, Study $3 \mathrm{c}$ demonstrated that an individual acting indecisively in general is not viewed as any more representative of agnostics compared with atheists, Christians, or Muslims. Thus, my hypothesis for Study 3a was partially supported and my hypotheses for Study $3 \mathrm{~b}$ and 3c were not supported. Possible explanations of these unexpected results are considered in the following section. 


\section{Chapter 5 \\ General Discussion}

The present studies helped uncover the stereotype content that exists for agnostics and how this content differs from atheists. Study 1 qualitatively assessed the stereotype content that Americans feel society holds about agnostics, atheists, Christians, and Muslims. With these results, I created dictionaries that contained the common stereotypes for each group. The benefit of these dictionaries is that they will become references for future studies that test differences between how individuals apply stereotypes to different religious and nonreligious groups. The most common stereotypes for agnostics included indecisive, faithless, questioning, nonreligious, confused, immoral, atheist, kind, science, and stupid; whereas, the most common stereotypes for atheists were immoral, intolerant, evil, satanic, arrogant, mean, nonreligious, faithless, rude, and bad.

In Study 2 I extended the findings of Study 1 by demonstrating how representative key traits generated in Study 1 were of agnostics, atheists, and various religious groups. Individuals perceived agnostics as safer, more loyal, more moral, more patriotic, more tolerant, and more trustworthy than atheists. In contrast, individuals viewed agnostics as younger, less brave, less safe, less decisive, less loyal, less moral, less patriotic, less predictable, and less trustworthy than Protestants. With the Bonferroni adjustment, agnostics were not rated as more tolerant than Protestants, but the p-value of less than .03 warrants future investigation. Similar to the comparisons with Protestants, agnostics were viewed as younger, less safe, less decisive, less loyal, less patriotic, less predictable, and less moral than Mormons. Finally, compared to Muslims, agnostics were perceived as safer, braver, less decisive, more moral, more patriotic, more predictable, more tolerant, and more trustworthy.

Lastly, Study 3 was a foundational step in uncovering whether agnostics are associated with immorality to the same degree as atheists by assessing conjunction error rates when people intuitively judged the group membership of an individual who was acting uninhibitedly immoral. Furthermore, Study 3 tested whether individuals associated indecisiveness with agnostics and whether this association is strictly for cases of immorality or if it generalizes across other domains as well. Results of Study 3a indicated that an immoral act was viewed as more representative of agnostics and atheists than or Christians and Muslims. Unexpectedly, there was no difference between the atheist and agnostic condition. For Study 3b, an individual struggling with whether to act immorally was seen as more representative of agnostics compared with Muslims, but no more representative of agnostics than atheists or Christians. Finally, in Study $3 c$ an individual acting indecisive in general was not viewed as anymore representative of agnostics compared with atheists, Christians, or Muslims.

\subsection{Stereotype Content}

\subsubsection{Immorality}

Study 1 and Study 2 both demonstrated that although agnostics are viewed as less immoral than atheists, they are not viewed as moral. This is in contrast to the results of Study 3a, which suggested that an immoral act was viewed as 
equally representative of atheists and agnostics. Given the results of Studies 1 and 2, I propose that the vignette used for Study 3a was not immoral enough to show a differentiation between atheists and agnostics. Because both groups are perceived as less moral than Christian denominations, committing a 'hit and run' or taking cash out of a lost wallet could be representative of both agnostics and atheists. However, if agnostics are viewed as immoral (Study 1) or sitting on the cusp of morality (Study 2), but less immoral than atheists (Studies 1 and 2), then differences in perceptions between the two groups may arise at increasing levels of immorality (e.g., rape or murder). Importantly, Gervais (2014) found that even relatively harmless immoral acts, such as cheating in a game of cards, is considered more representative of atheists than religious believers. Therefore, when it comes to seemingly innocuous immoral behaviours, individuals may believe that they have enough information to discriminate between an atheist and theist, but not between an atheist and an agnostic.

Furthermore, the vignette used for Study $3 \mathrm{~b}$ may suggest that struggling with morality occurs across various religious and nonreligious groups. Similar to Study 3a not being immoral enough to differentiate between atheists and agnostics, Study $3 \mathrm{~b}$ may not have been immoral enough to differentiate between atheists, agnostics, and Christians. Individuals may perceive struggling with morality to be universal; however, it is the decision that one arrives at that leaves an impression of their religious affiliation. Alternatively, variability in how participants interpret the individual in the vignette's indecisiveness may explain the unexpected results. Some participants may have interpreted his indecisiveness as signalling a lack of moral conviction; whereas, some participants may have interpreted his indecisiveness as a marker of reflection and lack of impulsivity. Previous research has provided evidence of participants rewarding an actor for taking his time before deciding on a course of action (e.g., Robinson et al., 2017). It is possible that in the vignette, the individual may have been perceived to be thoughtfully deliberating when possibly Christian, lacking moral conviction when possibly atheist, and indecisive when possibly agnostic. Future research needs to test these ideas.

\subsubsection{Indecisiveness}

As predicted for Study 1, indecisiveness was the most common stereotype associated with agnostics. It also resulted in the largest effect size difference between atheists and agnostics on all 26 tested traits. In Study 2, agnostics were rated as less decisive compared with every other group except, surprisingly, for atheists. Because agnostics neither believe nor disbelieve in God, it is reasonable that others would expect them be indecisive in many decisions in life. However, in Study 3, agnostics were rated as no less decisive than atheists or Christians. It is possible that Study 3's results deviated from Study 1 and Study 2 because choosing which graduate school to attend is a major decision that anyone could be seen to be indecisive about. Future research should examine whether indecisiveness about inconsequential choices (e.g., which laundry detergent to buy or which movie to watch) or major decisions that people tend to be decisive on (e.g., whether they want children) is viewed as more representative of agnostics than atheists or theists. Additionally, in the future I will assess whether participants perceive the actor to be indecisive or thoughtful given the actor's religious affiliation. 


\subsubsection{Tolerance}

In Study 1, agnostics were reported to be significantly more tolerant than Muslims and Christians, but not atheists. However, they were also reported to be significantly less intolerant than atheists, Christians, and Muslims. In contrast, Study 2's results indicated that agnostics are significantly more tolerant than atheists, but not Mormons or Protestants. However, a p-value of .026 for the agnostic/Protestant comparison warrants further investigation. Overall, the combined results of Study 1 and 2 suggest that agnostics are considered more tolerant than other religious and nonreligious groups. Slight inconsistencies in results may be due to the differences in methods, where in Study 1 participants reported the first/top traits that came to mind and in Study 2 they rated traits that were given to them. This means that stereotypes captured in Study 1 comprise the most salient traits of each group.

These two studies suggest that tolerance is a stereotype where atheists and agnostics diverge. If agnostics are viewed as more tolerant than atheists, then outgroup members will likely prefer to engage with agnostics, compared with atheists, on topics closely tied to religiosity. It is also possible that agnostics may feel more conversion pressures from religious individuals if they are perceived to be more tolerant than atheists toward religious groups. Future research should investigate how differences in perceptions of tolerance affect the way atheists and agnostics are approached.

\subsubsection{Bravery and Predictability}

Because agnostics do not deny theists' or atheists' viewpoints, I hypothesized that they would be considered the most cowardly of all the groups for not picking a side. Additionally, I hypothesized that because they are fencesitters, others would perceive them to be unpredictable because their behaviour may waver to side more with atheists or with theists depending on the situation. However, my hypotheses were not supported.

In Study 1, comparisons between agnostics and atheists, Christians, and Muslims on cowardice and fence-sitting lost its significance with the Holm adjustment to account for multiple pair-wise testing. Additionally, stereotypes of unpredictability were not generated at all for Study 1 . However, because participants could report no more than five traits per group, it was possible that participants still held stereotypes of cowardice and unpredictability toward agnostics; these stereotypes may just not be salient enough to be included in participants top five words.

Thus, Study 2 tested whether unpredictability and cowardice would be considered most representative of agnostics compared with all other groups when participants were given traits to rate rather than asked to generate traits. Again, results did not support my hypotheses. Agnostics were rated as less brave compared with only Protestants, not any other group. This suggests that agnostics fence-sitting is not perceived to be a result of being too afraid to voice one's true beliefs. Furthermore, agnostics were rated as more predictable than Muslims, and no less predictable than atheists. Both traits were more closely correlated to perceptions of morality and trustworthiness than indecisiveness, suggesting that fence-sitting is not associated with cowardice or unpredictability. Finally, it is also possible that some participants may perceive agnostics to be braver than other groups because of their willingness to stand against 
conventional norms. Therefore, in future work I will assess participants' rationales for their bravery or cowardice judgements of agnostics.

\subsubsection{Trustworthiness, Danger, and Loyalty}

I hypothesized that atheists and agnostics would be perceived to be the least trustworthy and loyal compared with all other groups. Contrastingly, I predicted that Muslims would be considered the most dangerous group. Surprisingly, Study 1 showed no differences in untrustworthiness between agnostics, atheists, Christians, or Muslims. These findings are inconsistent with Gervais et al. (2011), who found that distrust is central to the types of discrimination that atheists experience. Consistent with my hypotheses, danger was one of the most frequent stereotypes for Muslims, but not atheists, agnostics, or Christians. Finally, loyalty was not generated for any of the groups in Study 1. Again, because Study 1 asked for a reporting of up to only five words, it is possible that individuals considered atheists and agnostics to be untrustworthy, dangerous, and disloyal, but other traits were more salient to their schemas and, therefore, listed first.

Thus, Study 2 tested whether untrustworthiness and disloyalty would be considered most representative of agnostics and atheists compared with all other groups when participants were given traits to rate rather than asked to generate traits. Furthermore, it assessed whether Muslims would again be considered the most dangerous of the groups.

Overall, results supported my hypotheses for loyalty. Atheists and agnostics were rated less loyal than Protestants. However, contrary to my hypothesis, Muslims were not considered more loyal than atheists and agnostics; although a small p-value of .003 for the agnostic-Muslim condition warrants further investigation. Agnostics were rated as more loyal than atheists, suggesting that fence-sitting does not result in agnostics being perceived as more disloyal than atheists. As expected, atheists and agnostics were rated as less trustworthy than Christian denominations. Unexpectedly, Muslims were rates as less trustworthy than atheists and agnostics. Finally, as predicted and consistent with Study 1, Muslims were rated the most dangerous of all groups. Agnostics were rated as more trustworthy than atheists, but less trustworthy than Christian denominations.

In sum, agnostics were viewed as safer, more loyal, and more trustworthy than atheists. However, all of these effect sizes were small $\left(r_{p b}<.2\right)$, so future research will need to test whether these variations in stereotype content translate into different experiences of discrimination. If these small effect sizes are pragmatically significant, then atheists are likely at a greater disadvantage than agnostics for being hired for jobs that stress loyalty, trustworthiness, and safety (e.g., police officers and politicians).

\subsection{Definitional Concerns}

In Study 1, I investigated the proportion of individuals who correctly defined agnosticism. Results indicated 13\% of individuals conflated agnosticism with atheism and only $55 \%$ of individuals correctly defined agnosticism. In addition to participants' struggle to define agnosticism, interrater reliability $(\kappa=.61)$ was also a concern for this 
study. Therefore, categorizing agnostic definitions as correct, incorrect, or conflated with atheism is difficult even among RAs who used Wikipedia definitions to make judgments.

Definitional concerns and disagreement could be used to support the argument that agnosticism should not be included in research questions about belief. Because agnosticism-Gnosticism lies on a different dimension than atheism-theism, agnosticism in this sense is not mutually exclusive with atheism or theism. However, I maintain that the significant proportion of individuals who identify as strictly agnostic, not atheist nor theist, warrants the need for further investigation.

Nationally representative data from the American Religious Identification Survey (ARIS; 2008) also suggests that in everyday life people conflate gnosticism with theism. For example, Cragun et al. (2012) found that even among atheists and agnostics themselves, their theological identification and their self-identified labels of 'atheist' or 'agnostic' were discrepant. More specifically, they found that among self-identified agnostics, theologically $60 \%$ were agnostic, 30\% were deist (i.e., God exists but is not involved in human affairs), 3\% were atheists, and 5\% were theists. Among self-reported atheists, theologically 56\% were atheists, 30\% were agnostics, 5\% were deists, and $9 \%$ were theists. These findings highlight the difficulty in studying nonreligious groups as both outgroup and ingroup members struggle to define atheism and agnosticism. Interestingly, for Study 1 and Study 3 there were no differences in stereotype generation or proportion of conjunction errors depending on whether participants were provided with a definition of agnosticism despite, almost half of participants in Study 1 giving an incorrect definition of agnosticism.

Keeping in mind the challenges surrounding defining these constructs, in my future line of research I will need to take into consideration whether participants should receive a working definition of agnosticism, receive the label, or receive the definition and label for each study. It is reasonable to argue that if individuals are not clear on what an agnostic is, then researchers should provide participants with a definition in order to be sure that their judgments are not affected by misconceptions about what defines agnostics. However, one may also argue that individuals do not receive definitions in everyday life; therefore, providing only a label for this group would more accurately represent real-world experiences.

\subsection{Limitations}

Study 3a tested whether providing a definition for agnosticism versus providing a label for the group made a difference in conjunction errors. However, in Study $3 \mathrm{a}$ and $3 \mathrm{~b}$ I provided participants only with the definitions for agnostics and atheists. As previously mentioned, this created a limitation because in real-life situations, individuals likely do not receive definitions for these groups before making their judgments. Additionally, choosing which definition to provide to participants presented another issue. In future studies I will test whether using different definitions for agnosticism (e.g., believes the existence of God is unknown versus neither believes nor disbelieves in God) affects perceptions of this group. 
Another limitation of this study is that participants may have made conjunction errors less often than they normally would for the Muslim condition because they may believe competitive swimming is unrepresentative of Muslims in general. I chose to have the individual in the vignette be a competitive swimmer because the option had to be realistic for a graduate school applicant to engage in and it had to be an activity that would work across the three conjunction fallacy studies. In hindsight, I should have chosen an alternative that is not tied to any pre-conceived notions of the type of groups that engage in the behaviour.

\subsection{Implications and Future Directions}

It is evident that nonreligious individuals face significant levels of discrimination in society. For example, Cragun et al. (2012) found that $41.2 \%$ of self-identified atheists and $44.0 \%$ of self-identified agnostics experienced discrimination over the past five years from their family, workplace, school/college, the military, volunteer organization/clubs, and/or socially. Cragun and colleagues also found that atheists and agnostics were most likely to experience discrimination socially (26.1\%), followed by the workplace (14.2\%), school (13.0\%), and family $(12.9 \%)$. However, differences in discriminatory experiences between atheists and agnostics were not examined.

Therefore, once we gain a better understanding of the stereotypes that are associated with atheists and agnostics, we can begin hypothesizing which ones, in addition to immorality, drive different types of discriminatory behaviour. We can also investigate whether the discrimination experiences of atheists and agnostics differ. For example, if agnostics are viewed as untrustworthy, immoral, and indecisive, they may face even greater discrimination in politics compared with atheists, who are viewed as untrustworthy and immoral. With knowledge on how discriminatory experiences differ between the two groups, we can create targeted interventions to reduce discrimination toward atheists and agnostics as separate groups.

In addition, I aim to expand on morality research by investigating whether atheists, agnostics, Christians, and Muslims are expected to make consequentialist versus deontological judgments when faced with moral dilemmas. Previous literature has shown that when an individual is faced with a moral dilemma and takes a consequentialist position (i.e., for the greater good) quickly, they are viewed as less moral than someone who takes a deontological position (i.e., aligns with societal rules; Robinson, Page-Gould, \& Plaks, 2017). However, this difference is attenuated if the individual undergoes great effort before taking a consequentialist position. Based on this, I want to test if individuals who make rash consequential decisions are more likely to be viewed as atheists because atheists are associated with a stereotype of immorality. Furthermore, individuals who put in a lot of effort before making a consequentialist decision may be more likely to be viewed as an agnostic. Such a finding would occur if people view agnostics as indecisive. Finally, individuals who take a deontological position, regardless of amount of effort exerted, may be more likely to be viewed as a theist.

To expand on applications of distrust stereotypes, I aim to place individuals in situations where the stereotype becomes relevant. For example, one way to assess whether Christians view agnostics or Muslims as untrustworthy is to place them in a situation where trust is at stake. The Prisoner's Dilemma is a situation that stresses cooperation 
from both parties in order to maximize reward. Previous research has found that individuals are most cooperative playing with others from the same religious background (Chuah, Hoffman, Ramasamy, \& Tan, 2014). It is of interest to determine whether Christians, the majority group in North America, create a hierarchy of trust when interacting with individuals of opposing religious views. These types of investigations are important as they can help decipher which members of opposing religious groups Christians will be most likely to cooperate with during situations when maintaining trust is critical to achieving a common goal (e.g., when citizens must have faith in their leaders, even when those leaders have incongruent religious views).

\subsection{Conclusion}

This series of studies was a fundamental first step in uncovering the stereotypes of agnostics and investigating how they differ from atheists and other religious groups. In summary, agnostics were generally viewed as indecisive (except in Study 3) and tolerant. On many traits, such as morality, danger, loyalty, patriotism, and trustworthiness, agnostics were viewed more positively than atheists and less positively than Protestants. However, even though stereotype content differed between atheists and agnostics, effect sizes were small. This means that future research will need to assess whether these differences in stereotype content translate into any differences in discrimination experiences. 


\section{References}

Burton, C. (2016). Three foundations of American conservative political orientation: Masculine independence, religious traditionalism, and ethnic separateness. Unpublished doctoral dissertation, University of Toronto, Toronto, ON.

Branscombe, N.R., Schmitt, M.T., \& Harvey, R.D. (1999). Perceiving pervasive discrimination among African Americans: Implications for group identification and well-being. Journal of Personality and Social Psychology, 77, 135-149. doi:10.1037/0022-3514.77.1.135

Chuah, S-H., Hoffman, R., Ramasamy, B., Tan, J.H.W. (2014). Religion, ethnicity, and cooperation: An experimental study. Journal of Economic Psychology, 45, 33-43.

doi:https://doi.org/10.1016/j.joep.2014.07.002

Cook, C. L., Cottrell, C. A., \& Webster, G. D. (2015). No good without God: Antiatheist prejudice as a function of threats to morals and values. Psychology of Religion and Spirituality, 7, 217-226. doi:http://dx.doi.org/10.1037/rel0000013

Cottrell, C. A., \& Neuberg, S. L. (2005). Different emotional reactions to different groups: A sociofunctional threatbased approach to "prejudice." Journal of Personality and Social Psychology, 88, 770-789. doi:10.1037/0022-3514.88.5.770

Cragun, R. T., Kosmin, B., Keysar, A., Hammer, J. H., \& Nielsen, M. (2012). On the receiving end: Discrimination toward the non-religious in the United States. Journal of Contemporary Religion, 27, 105-127. doi:10.1080/13537903.2012.642741

Dawkins, R. (2006). The god delusion. Boston, New York: Houghton Mifflin.

DeYoung, C.G., Quilty, L.C., Peterson, J.B. (2007). Between facets and domains: 10 aspects of the Big-Five. Journal of Personality and Social Psychology, 93, 880-896. doi:10.1037/0022-3514.93.5.880

Doane, M. J., \& Elliot, M. (2015). Perceptions of discrimination among atheists: Consequences for atheist identification, psychological, and physical well-being. Psychology of Religion and Spirituality, 7, 130-141. doi:http://dx.doi.org/10.1037/rel0000015

Edgell, P., Gerteis, J., \& Hartmann, D. (2006). Atheists as “other”: Moral boundaries and cultural membership in American society. American Sociological Review, 71, 211-234. 
Franks, A. S., \& Scherr, K. C. (2014). A sociofunctional approach to prejudice at the polls: Are atheists more politically disadvantaged than gays and Blacks? Journal of Applied Social Psychology, 44, 681-691. doi:10.1111/jasp. 12259

Galen, L. W., Williams, T. J., \& Ver Way, A. L. (2014). Personality ratings are influenced by religious stereotype and ingroup bias. The International Journal for the Psychology of Religion, 24, 282-297.

Gervais, W.M. (2013). In Godlessness we distrust: Using social psychology to solve the puzzle of anti-atheist prejudice. Social and Personality Psychology Compass, 7, 366-377. doi:10.1111/spc3.12035

Gervais, W. M. (2014). Everything is permitted? People intuitively judge immorality as representative of atheists. PLOS ONE, 9, e92302.

Gervais, W. M. (n.d.). “I'm not an atheist...I'm an agnostic”. Retrieved from http://willgervais.com/blog/2017/1/24/im-not-an-atheistim-an-agnostic

Gervais, W. M., Shariff, A. F., \& Norenzayan, A. (2011). Do you believe in atheists? Distrust is central to antiatheist prejudice. Journal of Personality and Social Psychology, 101, 1189-1206. doi:10.1037/a0025882

Giddings, L., \& Dunn, T. J. (2016). The robustness of anti-atheist prejudice as measured by way of cognitive errors. The International Journal for the Psychology of Religion, 26, 124-135.

Goodstein, L. (2014, December 6). In 7 States, Atheists Fight for Removal of Belief Rule. New York Times, p. A23

Gosling, S.D., Rentfrow, P.J., \& Swann Jr., W.B. (2003). A very brief measure of the Big-Five personality domains. Journal of Research in Personality, 37, 504-528.

Graham, J., \& Haidt, J. (2010). Beyond beliefs: Religions bind individuals into moral communities. Personality and Social Psychology Review, 14, 140-150. doi:10.1177/1088868309353415

Graham, J., Nosek, B.A., Haidt, J., Iyer, R., Koleva, S., \& Ditto, P.H. (2011). Mapping the moral domain. Journal of Personality and Social Psychology, 101, 366-385. doi:10.1037/a0021847

Haidt, J., \& Graham, J. (2007). When morality opposes justice: Conservatives have moral intuitions that Liberals may not recognize. Social Justice Research, 20, 98-116. doi:10.1007/s11211-007-0034-z

Hammer, J. H., Cragun, R. T., Hwang, K., \& Smith, J. M. (2012). Forms, frequency, and correlates of perceived anti-atheist discrimination. Secularism \& Nonreligion, 1, 43-67. doi:10.5334/snr.ad

Harper, M. (2007). The stereotyping of nonreligious people by religious students: Contents and subtypes. Journal for the Scientific Study of Religion, 46, 539-552. doi:10.1111/j.1468-5906.2007.00376.x 
Jetten, J., Branscombe, N. R., Schmitt, M. T., \& Spears, R. (2001). Rebels with a cause: Group identification as a response to perceived discrimination from the mainstream. Personality and Social Psychology Bulletin, 27, 1204-1213. doi:10.1177/0146167201279012

Jones, J. M. (2012). Atheists, Muslims See Most Bias as Presidential Candidates. Gallup News Service. Retrieved from http://news.gallup.com/poll/155285/atheists-muslims-bias-presidential-candidates.aspx

Pew Research Center (May, 2015). America's changing religious landscape. Retrieved from http://www.pewforum.org/2015/05/12/americas-changing-religious-landscape/

Pew Research Center. (2014). For 2016 hopefuls, Washington experience could do more harm than good: Military service top positive, atheism top negative for potential candidates. Retrieved from http://www.peoplepress.org/files/ legacy-pdf/5-19-14\%20Presidential\%20Traits\%20Release.pdf

Pew Research Center (October, 2012). "Nones" on the rise. Retrieved from http://www.pewforum.org/2012/10/09/nones-on-the-rise/

Piazza, J., Bering, J. M., \& Ingram, G. (2011). "Princess Alice is watching you":Children's belief in an invisible person inhibits cheating. Journal of Experimental Child Psychology, 109, 311-320. doi:10.1016/j.jecp.2011.02.003

Pichon, I., Boccato, G., \& Saroglou, V. (2007). Nonconscious influences of religion on prosociality: A priming study. European Journal of Social Psychology, 37, 1032-1045. doi:10.1002/ejsp.416

Pronin, E., Lin, D.Y., \& Ross, L. (2002). The bias blind spot: Perceptions of bias in self versus others. Personality and Social Psychology Bulletin, 28, 369-381. doi: 10.1177/0146167202286008

Robinson, J. S., Page-Gould, E., \& Plaks, J. E. (2017). I appreciate your effort: Asymmetric effects of actors' exertion on observers' consequentialist versus deontological judgments. Journal of Experimental Social Psychology, 73, 50-64. doi:http://dx.doi.org/10.1016/j.jesp.2017.06.005

Robinson, J.S., Xu, X. \& Plaks, J.E. (in press). Disgust and deontology: Trait sensitivity to pathogens promotes a preference for clarity, hierarchy, and rule-based moral judgment. Social Psychological and Personality Science.

Shariff, A. F., \& Norenzayan, A. (2007) God is watching you: Priming God concepts increases prosocial behavior in an anonymous economic game. Psychological Science, 18, 803-809. Doi: 10.1111/j.14679280.2007.01983.x

Sibley, C. G., \& Duckitt, J. (2008). Personality and prejudice: A meta-analysis and theoretical review. Personality and Social Psychology Review, 12, 248-279. doi:10.1177/1088868308319226 
Sides, J., \& Gross, K. (2013). Stereotypes of Muslims and support for the war of on terror. The Journal of Politics, 75, 583-598. doi:10.1017/S0022381613000388

Simpson, A., Piazza, J., \& Rios, K. (2016). Belief in divine moral authority: Validation of a shortened scale with implications for social attitudes and moral cognition. Personality and Individual Differences, 94, 256-265. doi:10.1016/j.paid.2016.01.032

Tversky, A., \& Kahneman, D. (1983). Extension versus intuitive reasoning: The conjunction fallacy in probability judgment. Psychol Rev, 90, 293-315.

Wright, J., \& Nichols, R. (2014). The social cost of atheism: How perceived religiosity influences moral appraisal. Journal of Cognition and Culture, 14, 93-115.

Zafar, S., \& Ross, E. C. (2015). Interreligious contact, attitudes, and stereotypes: A study of five religious groups in Canada. Canadian Journal of Behavioural Science, 47, 37-46. doi:http://dx.doi.org/10.1037/a0036720 


\title{
Appendices
}

\author{
Appendix A \\ Definitions
}

Study 1 Definitions:

Agnostic: An agnostic is someone who believes that God's existence is unknown.

Atheist: An atheist is someone who believes that there is no God.

Christian: A Christian is someone who believes there is a God and follows the teachings of Jesus Christ.

Muslim: A Muslim is someone who believes there is a God and follows the teachings of Muhammad.

Study 2 Definitions:

Agnostic: Agnostics believe that God's existence is unknown.

Atheist: Atheists believe that there is no God.

Mormon: Mormons believe in a single God and are part of the Church of Jesus Christ of Latter Day Saints.

Mormons follow the teachings of the Bible and of the Book of Mormon.

Muslim: Muslims believe in a single God and follow the teachings of Muhammad.

Protestant: Protestants believe in a single God and are Christians. Several churches are Protestant, including the Baptist, Presbyterian, and Lutheran churches.

Seventh-Day Adventist: Seventh-day Adventists believe in a single God. They are distinguished by their observance of Saturday as the Sabbath (rather than Sunday). 
Appendix B

Study 1 - Generated Definitions for Agnostics and Atheists

\section{Agnostics:}

Someone who believes faith cannot be proven and therefore whether God exists or not is a mystery

Unsure of gods existence

Believe in anything and nothing*

Don't believe in $\operatorname{god}^{* *}$

Someone who isn't sure or doesn't care about religious matters*

Someone who doesn't know or care whether there is a God or not

Is someone to me who remains neutral and doesn't know what to believe if anything

Someone who isn't sure what to believe

Someone who doesn't believe in anything*

Someone who doesn't have a specific religion but doesn't deny that there is some sort of spiritual/religious truth*

Not sure if God is real

Someone who doesn't know if there is a god

Someone who doesn't know what to believe*

Someone who is unsure of the existence of God but does not necessarily doubt it entirely

Someone who believes in space*

Someone who isn't sure if there is a god and/or doesn't believe it is possible to know

Agnostic believes in a higher power*

A person who isn't sure of a god or otherwise

One who does not believe in a deity but may/may not believe in some existence of a god or creator* 
Acknowledging the thought of without believing in*

It means that you don't know if there is a God, so you don't really think about it or let it affect your life

Someone who believes that it cannot be proven whether a god exists or not

A person who is unsure about the existence of God

A person who doesn't believe in a god because s/he doesn't know if a God exists or not, it's not proven

Someone that questions the belief of God**

An agnostic is someone who proclaims either than they do not have enough information to determine whether there is a god or that it is impossible to know whether there is a god

Someone who is just not sure if there is a God or Higher Power

Someone who is skeptical about God**

Someone who is not sure whether there is a god

Someone who believes there is a god but does not have a religious affiliation*

An agnostic is someone who doesn't believe or disbelieve in God

Doesn't believe in anything*

Someone who doesn't know if there's a God or not till they have proof

Someone who doesn't believe or disbelieve in god or gods

Someone who refrains from choosing to believe or disbelieve in god or gods, based largely upon the idea that to do otherwise, would assume facts not in evidence

A person who refuses the idea of religion*

Someone who is not sure if there is a God but does not discount the possibility

Someone who doesn't believe what they think can be 100 percent true.

A person who is waiting for evidence as to whether or not to believe in a higher power 
Has no faith and believes in nothing**

No faith in God**

Someone who is not sure whether God exists or not

Someone who is unsure of the god situation and would need proof one way or another to really decide

I do not know what an agnostic is*

An agnostic is a person who does not care whether there is a god or not

A person who does not believe in God but is willing to be proven wrong*

Someone who does not believe in god

People who don't know if God exist or not.

People who don't think the existence of God is unknown*

Someone who is still searching for a creator*

Feminist*

Believes they do not know the answer

Someone who can't decide what they are but want a title anyways*

Meaning I don't believe in a GOD

Note. *incorrect; ${ }^{* *}$ conflated with atheism

\section{Atheists:}

A person who definitively believes there is no God or higher entity

Someone who doesn't believe god

No belief in a god

Don't believe 
Someone who has no faith in any religion

Someone who believes there is no God, and no absolute right or wrong*

A person who does not believe in the existence of God

Someone who doesn't believe in God

Someone who doesn't believe in God

Someone who doesn't believe in any religion and believes that there is no spiritual/religious truth

Doesn't believe in God

Someone who doesn't believe in god

A non-believer of any religion

Someone who does not believe in God or organized religion whatsoever

An unbeliever

Someone who does not believe there is a god or gods

A person that doesn't believe in God

A person who doesn't believe in any god

A person that doesn't believe in god

A non-believer in a deity or creator

A person who denies existence of all deities or religious entities

An atheist is someone who doesn't believe that there is a god or gods at all

A person who doesn't believe a god exists

A person who does not believe in any gods or deities

A person who doesn't believe in God 
Someone that does not believe in God

Literally speaking, an atheist person who does not believe that there is a god that intervenes in worldly affairs.

More commonly, an atheist is a person who does not believe in god

Someone who does not believe a God or higher power exists

Someone who doesn't believe in God

Someone who believes that there is no god

Someone who does not believe anything unless evidence is clear

An atheist is someone who does not believe in the existence of God

Someone who does not believe in a higher being. believes in science to explain all things

Someone that doesn't believe in a God

Someone who does not believe in any god

Someone who chooses not to believe in god, ostensibly based upon the idea that there is no proof of such and that modern scientific theories sufficiently explain the origins of the universe

Someone who does not believe in a God or Gods and doesn't believe in religion

Someone who does not believe in the existence of God of God's, not religious

Someone who does not believe in the existence of god

A person who does not believe in god or a higher power

Doesn't believe in God*

Someone who does not believe in God

Someone who does not believe in the existence of God

Someone who believes there is no god and no possibility of one

Does believe in god 
An atheist is a person who does not believe that there is a god

Someone who adamantly denies any deity at all

Someone who doesn't people in god

Someone who doesn't believe in God

A person that doesn't believe in God

Who is firm in her beliefs that there isn't a god

Non-believer

Someone who doesn't believe in a higher power or god

Someone who does not believe in any sort of god/afterlife

Someone who doesn't believe in god, but wishes they had a religious title

Means they do not believe in everyone else's god yet still believes in heaven and hell?*

Note. *incorrect 
Appendix C

Study 1 Dictionary

\begin{tabular}{|c|c|c|c|c|}
\hline Word & Agnostic & Atheist & Christian & Muslim \\
\hline accent & 0 & 0 & 0 & 3 \\
\hline agnostic & 0 & 3 & 0 & 0 \\
\hline America* & 0 & 0 & 2 & 0 \\
\hline angry & 1 & 8 & 0 & 5 \\
\hline annoying & 1 & 4 & 3 & 1 \\
\hline anti-science & 0 & 0 & 6 & 0 \\
\hline arrogan* & 11 & 20 & 8 & 0 \\
\hline atheis* & 16 & 0 & 0 & 0 \\
\hline awesome & 2 & 0 & 2 & 0 \\
\hline backwards & 1 & 1 & 0 & 14 \\
\hline bad & 5 & 14 & 1 & 5 \\
\hline bad tastes & 0 & 0 & 0 & 3 \\
\hline beard* & 0 & 1 & 0 & 3 \\
\hline blasphem* & 2 & 0 & 0 & 0 \\
\hline boring & 2 & 0 & 3 & 1 \\
\hline Brown & 0 & 0 & 0 & 11 \\
\hline Cathol* & 0 & 0 & 3 & 0 \\
\hline cautio* & 3 & 0 & 0 & 0 \\
\hline charitable & 0 & 0 & 28 & 0 \\
\hline
\end{tabular}




\begin{tabular}{|c|c|c|c|c|}
\hline Word (Cont'd) & Agnostic & Atheist & Christian & Muslim \\
\hline closed-minded & 3 & 3 & 8 & 2 \\
\hline cold* & 3 & 10 & 0 & 1 \\
\hline collectiv* & 0 & 0 & 0 & 2 \\
\hline colourful & 1 & 1 & 0 & 0 \\
\hline combative & 2 & 3 & 0 & 1 \\
\hline confiden* & 1 & 2 & 2 & 1 \\
\hline confus* & 17 & 4 & 0 & 0 \\
\hline conservativ* & 0 & 0 & 19 & 5 \\
\hline contemplative & 2 & 0 & 0 & 0 \\
\hline control* & 0 & 2 & 3 & 3 \\
\hline correct & 0 & 0 & 2 & 0 \\
\hline coward* & 8 & 0 & 0 & 1 \\
\hline craz* & 2 & 1 & 1 & 6 \\
\hline curious & 7 & 0 & 0 & 0 \\
\hline danger* & 0 & 2 & 0 & 30 \\
\hline degenerate & 0 & 3 & 1 & 2 \\
\hline denial & 1 & 1 & 0 & 0 \\
\hline devot* & 0 & 0 & 4 & 7 \\
\hline different & 2 & 1 & 0 & 4 \\
\hline directionless & 5 & 3 & 0 & 0 \\
\hline does not believe in Jesus Christ & 0 & 0 & 0 & 2 \\
\hline
\end{tabular}




\begin{tabular}{|c|c|c|c|c|}
\hline Word (Cont'd) & Agnostic & Atheist & Christian & Muslim \\
\hline does not eat meat & 0 & 0 & 0 & 2 \\
\hline don't belong & 1 & 0 & 0 & 2 \\
\hline ethical & 0 & 0 & 5 & 1 \\
\hline evangelical & 0 & 0 & 2 & 0 \\
\hline evidence & 2 & 0 & 0 & 0 \\
\hline evil & 6 & 25 & 0 & 13 \\
\hline extrem* & 0 & 0 & 5 & 9 \\
\hline faithful & 3 & 0 & 13 & 1 \\
\hline faithless & 32 & 18 & 0 & 1 \\
\hline family-oriented & 0 & 0 & 4 & 0 \\
\hline fence-sitters & 6 & 0 & 0 & 0 \\
\hline filth* & 2 & 0 & 0 & 12 \\
\hline foreign & 0 & 0 & 0 & 9 \\
\hline gas station owners & 0 & 0 & 0 & 3 \\
\hline God & 0 & 0 & 2 & 0 \\
\hline good* & 1 & 0 & 11 & 1 \\
\hline goth* & 2 & 3 & 0 & 0 \\
\hline hard & 0 & 2 & 0 & 0 \\
\hline hard-headed & 2 & 5 & 3 & 11 \\
\hline hedonis* & 1 & 2 & 0 & 0 \\
\hline hellbound & 7 & 6 & 0 & 0 \\
\hline
\end{tabular}




\begin{tabular}{|c|c|c|c|c|}
\hline Word (Cont'd) & Agnostic & Atheist & Christian & Muslim \\
\hline hippy & 2 & 1 & 0 & 0 \\
\hline hipster & 1 & 1 & 0 & 0 \\
\hline holy & 0 & 0 & 10 & 1 \\
\hline honest & 3 & 2 & 9 & 2 \\
\hline hopeful & 1 & 0 & 4 & 0 \\
\hline hopeless & 5 & 8 & 0 & 0 \\
\hline humble & 2 & 0 & 3 & 0 \\
\hline humorous & 2 & 1 & 0 & 0 \\
\hline hypocrit* & 0 & 1 & 21 & 1 \\
\hline ignoran* & 8 & 5 & 7 & 1 \\
\hline immoral* & 16 & 36 & 0 & 1 \\
\hline indecisive & 44 & 1 & 0 & 0 \\
\hline indifferent & 6 & 1 & 0 & 0 \\
\hline individual* $^{*}$ & 3 & 2 & 0 & 0 \\
\hline intell* & 11 & 8 & 3 & 2 \\
\hline intoleran* & 11 & 33 & 29 & 70 \\
\hline irrational & 2 & 0 & 4 & 1 \\
\hline Jihad* & 0 & 0 & 0 & 3 \\
\hline judg* & 1 & 2 & 24 & 0 \\
\hline kind* & 15 & 1 & 50 & 2 \\
\hline lazy & 4 & 0 & 0 & 0 \\
\hline
\end{tabular}




\begin{tabular}{|c|c|c|c|c|}
\hline Word (Cont'd) & Agnostic & Atheist & Christian & Muslim \\
\hline liberal & 2 & 6 & 1 & 0 \\
\hline loud* & 1 & 3 & 0 & 1 \\
\hline mean* & 7 & 20 & 3 & 9 \\
\hline misunderstood & 0 & 3 & 0 & 3 \\
\hline modern & 1 & 1 & 0 & 0 \\
\hline moral* & 0 & 0 & 13 & 0 \\
\hline negative & 1 & 4 & 1 & 0 \\
\hline neutral & 7 & 0 & 0 & 0 \\
\hline nihilist & 0 & 2 & 0 & 0 \\
\hline nonreligious & 19 & 18 & 0 & 0 \\
\hline normal & 0 & 1 & 3 & 0 \\
\hline obidien* & 0 & 0 & 2 & 0 \\
\hline peace* & 0 & 0 & 4 & 1 \\
\hline pious & 0 & 0 & 6 & 0 \\
\hline pitiful & 1 & 0 & 1 & 0 \\
\hline pliable & 2 & 0 & 0 & 2 \\
\hline polygam* & 0 & 0 & 1 & 1 \\
\hline poor & 0 & 0 & 0 & 2 \\
\hline prolife & 0 & 0 & 2 & 0 \\
\hline proud & 0 & 2 & 2 & 0 \\
\hline prude & 0 & 0 & 8 & 0 \\
\hline
\end{tabular}




\begin{tabular}{|c|c|c|c|c|}
\hline Word (Cont'd) & Agnostic & Atheist & Christian & Muslim \\
\hline pure* & 0 & 1 & 4 & 1 \\
\hline pushy & 0 & 7 & 20 & 4 \\
\hline questioning & 22 & 12 & 0 & 0 \\
\hline rational & 11 & 7 & 0 & 0 \\
\hline rebellious & 4 & 9 & 0 & 5 \\
\hline reckless & 3 & 8 & 0 & 0 \\
\hline religio* & 0 & 0 & 43 & 15 \\
\hline religious headwear & 0 & 0 & 0 & 15 \\
\hline role model & 0 & 0 & 2 & 0 \\
\hline rude & 3 & 15 & 3 & 5 \\
\hline satan* & 7 & 23 & 0 & 0 \\
\hline scien* & 14 & 4 & 0 & 0 \\
\hline selfish & 6 & 6 & 3 & 2 \\
\hline serious* & 0 & 0 & 3 & 1 \\
\hline Sharia Law & 0 & 0 & 0 & 7 \\
\hline $\sin *$ & 8 & 7 & 1 & 5 \\
\hline socia* & 1 & 0 & 1 & 0 \\
\hline stupid & 14 & 12 & 11 & 5 \\
\hline superior & 0 & 2 & 6 & 0 \\
\hline superstitious & 0 & 0 & 2 & 1 \\
\hline terror* & 0 & 0 & 0 & 87 \\
\hline
\end{tabular}




\begin{tabular}{|c|c|c|c|c|}
\hline Word (Cont'd) & Agnostic & Atheist & Christian & Muslim \\
\hline threat* & 0 & 0 & 0 & 4 \\
\hline toleran* & 11 & 2 & 1 & 1 \\
\hline tradition* & 0 & 0 & 2 & 4 \\
\hline trustworthy & 0 & 0 & 2 & 0 \\
\hline ugly & 0 & 0 & 1 & 1 \\
\hline unethical & 2 & 7 & 1 & 2 \\
\hline unfaithful & 4 & 0 & 0 & 0 \\
\hline unholy & 2 & 6 & 0 & 1 \\
\hline unjust & 0 & 0 & 2 & 5 \\
\hline unknown & 1 & 1 & 0 & 0 \\
\hline unpatriotic & 1 & 4 & 0 & 0 \\
\hline unrealistic & 1 & 3 & 1 & 1 \\
\hline unreliable & 2 & 0 & 0 & 0 \\
\hline unsocial & 1 & 3 & 0 & 0 \\
\hline untrustworthy & 9 & 8 & 8 & 7 \\
\hline uptight & 3 & 2 & 2 & 0 \\
\hline violen* & 1 & 0 & 1 & 27 \\
\hline weak* & 5 & 1 & 1 & 0 \\
\hline wears fedoras & 0 & 2 & 0 & 0 \\
\hline weird & 7 & 1 & 1 & 2 \\
\hline White & 0 & 5 & 3 & 0 \\
\hline
\end{tabular}




\begin{tabular}{lllll}
\hline Word (Cont'd) & Agnostic & Atheist & Christian & Muslim \\
\hline will not eat pork & 0 & 0 & 0 & 3 \\
wrong & 6 & 10 & 3 & 2 \\
young & 9 & 4 & 0 & 0 \\
\hline
\end{tabular}


Appendix D

Study 1 - Chi-Square Results for Definitions Provided vs. Definitions Generated

Agnostics:

\begin{tabular}{|c|c|c|c|}
\hline Word & Definition Provided Count & $\begin{array}{l}\text { Definition Generated } \\
\text { Count }\end{array}$ & Chi-Square \\
\hline arrogan* & 9 & 2 & 3.4402 \\
\hline confused & 6 & 11 & 1.0177 \\
\hline faithless & 19 & 13 & 0.91012 \\
\hline hellbound & 7 & 0 & 5.3072 \\
\hline indecisive & 26 & 18 & 1.0339 \\
\hline questioning & 14 & 8 & 1.2589 \\
\hline satan* & 0 & 7 & 5.3072 \\
\hline untrustworthy & 8 & 1 & 4.1659 \\
\hline wrong & 6 & 0 & 4.2803 \\
\hline
\end{tabular}

Atheists:

\begin{tabular}{|l|l|l|l|}
\hline Word & Definition Provided Count & $\begin{array}{l}\text { Definition Generated } \\
\text { Count }\end{array}$ & Chi-Square \\
\hline bad & 4 & 10 & 1.9036 \\
\hline faithless & 4 & 14 & 4.8894 \\
\hline intoleran* & 20 & 13 & 1.2774 \\
\hline mean* & 14 & 6 & 2.6879 \\
\hline rude & 4 & 11 & 2.5706 \\
\hline
\end{tabular}




\begin{tabular}{|l|l|l|l|}
\hline satan* & 9 & 14 & 0.77447 \\
\hline $\sin *$ & 1 & 6 & 2.3588 \\
\hline
\end{tabular}

